\title{
Nominal licensing in caseless languages
}

Michelle Sheehan, Anglia Ruskin University \& Jenneke van der Wal, Harvard University

\begin{abstract}
This paper provides evidence for a kind of nominal licensing (Vergnaud licensing) in a number of morphologically caseless languages. Recent work on Bantu languages, has suggested that abstract Case or nominal licensing should be parameterised (Diercks 2012, Van der Wal 2015a). With this is mind, we critically discuss the status of Vergnaud licensing in six languages lacking morphological case and agreement. While Luganda appears to systematically lack a Vergnaud licensing requirement, Makhuwa more consistently displays evidence in favour of it, as do all of the analytic languages that we survey (Mandarin, Yoruba, Jamaican Creole and Thai). We conclude that, while it seems increasingly problematic to characterise nominal licensing in terms of uninterpretable/abstract Case features, we nonetheless need to retain a (possibly universal) notion of nominal licensing, the explanation for which remains opaque.
\end{abstract}

Keywords: nominal licensing, abstract Case, comparative syntax, syntactic diagnostics, Case Filter, parameters, Thai, Mandarin, Makhuwa, Luganda, Jamaican Creole, Yoruba.

\section{Nominal licensing and morphological marking}

Minimalist approaches, like their Government and Binding counterparts, often implicitly assume some version of nominal licensing, whereby, even in languages lacking morphological case, overt referential DPs are restricted in their distribution in certain cross-linguistically stable ways (Chomsky 1981, Vergnaud 1977/2008). ${ }^{1}$ While it is often called (abstract) 'Case', we refer to this phenomenon more neutrally as 'Vergnaud licensing' following Pesetsky (2014) for reasons that will become clear shortly (see also Sigurðsson 1991, McFadden 2004 amongst many others). According to mainstream generative theory, Vergnaud licensing accounts for the distribution of (overt referential) DPs and motivates phenomena such as A-movement (passivization, raising and, for some, Control). Recent proposals, however, have argued for parameterisation of this property (Harford Perez 1985, Markman 2009, Diercks 2012 and to some extent Baker 2015). Specifically, Diercks (2012) claims that some Bantu languages behave systematically as though they lack Vergnaud licensing, so that overt referential DPs are not subject to the same restricted distribution observed in other well-studied languages.

There has been much debate regarding the relationship between Vergnaud licensing and the salient morphological properties of case and agreement. While nominal licensing appears to be wholly divorced from

\footnotetext{
${ }^{1}$ We follow common practice here in referring to abstract Case with a capital and morphological case marking with lowercase.
} 
morphological case in some languages (e.g. Icelandic), in many other languages the two things appear to be closely related (e.g. French) or at least partially connected (e.g. Walpiri - Legate 2008). This general tendency has led to the characterization of this property in terms of uninterpretable/abstract Case features. It is perhaps for this reason that Vergnaud licensing has been most widely discussed in relation to languages with morphological case and agreement. What has been much less discussed is the status of Vergnaud licensing in caseless languages, both those which lack case but retain agreement and those lacking any such morphology. In this paper we focus precisely on this issue.

We first introduce the traditional motivations and diagnostics for nominal licensing in section 2, listing nine diagnostic properties which have been attributed to Vergnaud licensing in languages such as English. By applying these to two Bantu languages in section 3, we show that there is apparent variation in this family in terms of nominal licensing. Luganda, which is previously undescribed in relation to this issue, patterns with Zulu and the other languages discussed by Diercks (2012) in failing a number of the Vergnaud-licensing diagnostics, whereas Makhuwa, recently described by Van der Wal (2015a), consistently behaves as though its nominals must be licensed. These two languages both lack morphological case but display rich agreement and provide apparent evidence for the parameterisation of this property in the Bantu family. We then, in section 4, consider four languages which have been classified as analytic because of their virtual lack of case/agreement morphology (Thai, Yoruba, Mandarin and Jamaican Creole) and assess their behavior with respect to Vergnaud licensing, before dismissing certain diagnostics as inapplicable or unreliable in section 5. Although the diagnostics, which we adopt and adapt from the literature, face certain challenges when applied to these languages, we nonetheless conclude that these languages all pattern with Makhuwa rather than Luganda in displaying evidence of Vergnaud licensing. Section 6 summarises the results and reassesses the status of Vergnaud licensing in current theory, given these facts.

\section{The evidence for Vergnaud licensing}

Vergnaud (1977/2008) famously observed that morphological case in richly inflecting languages like Latin tracks very closely the distribution of overt nominals in languages lacking such morphology (e.g. English). This gave rise to the abstract Case proposal, one of the cornerstones of Government and Binding Theory, whereby nominals, unlike other phrases, require 'licensing' under government by a heterogeneous set of categories (transitive $\mathrm{V}$, finite $\mathrm{T}$, non-finite $\mathrm{C}$ and $\mathrm{P}$ ). This requirement for nominal licensing is known as the 'Case Filter', and has recently been referred to as 'Vergnaud licensing' to distinguish it from the processes determining morphological case (Pesetsky 2014). The reason for this is that it has long been known that in some well-studied languages morphological case does not track nominal licensing in all instances.

Icelandic is a good example of this (see Andrews 1976, Zaenen, Maling and Thráinsson 1985, Sigurðsson 1991 amongst others), but the problem also arises in 'morphologically ergative languages', which have the same A- and A-bar properties as accusative languages (Anderson 1976, Legate 2008, 2012 amongst 
many others). A full discussion of mismatches between case morphology and Vergnaud licensing would take us too far afield (see McFadden 2004 for extensive discussion). Note, however, that even in Icelandic, it has been argued that nominals still require Vergnaud licensing, though this functions independently of morphological case (Sigurðsson 1991, 2012).

In Icelandic, quirky dative objects are not inherently licensed, since they can raise to a subject position in passives, as illustrated in (1) (see Zaenen, Maling and Thráinsson 1985 for convincing evidence that the dative is a genuine subject). As such, it is immediately clear that morphological case is distinct from Vergnaud licensing in the language. Moreover, quirky dative subjects of nonfinite clauses are subject to further licensing constraints (compare (2) and (3)):

(1) Honum var hjálpað

[Icelandic]

him.DAT was helped

'He was helped.' (Zaenen, Maling and Thráinsson 1985: 442)

(2) Hún taldi [einhverjumbátum hafa verið bjargað].

she believed some.DAT boats.DAT have.INF been rescued

'She believed some boats to have been rescued.'

$\begin{array}{lllll}\text { *Pað }^{2} \text { var talið [einhverjumbátum hafa verið } & \text { bjargað]. } \\ \text { there } & \text { was believed some.DAT boats.DAT } & \text { have.INF } & \text { been } & \text { rescued }\end{array}$

(Sigurðsson 1991: 358) ${ }^{2}$

While the subjects in both (2) and (3) have quirky dative case, this does not, famously, serve to license them. In (2), the dative subject is presumably licensed by the matrix transitive verb via ECM. In (3), however, the matrix verb is intransitive and so the result is ungrammaticality (although an in-situ dative would be licensed in object base position as the associate of the expletive). While this is strong evidence against a close connection between morphological case and nominal licensing, as many have noted, it is arguably evidence for a more abstract nominal licensing requirement (see Sigurðsson 2012 for this conclusion and a recent take on this issue).

Now consider ergativity. It is worth noting that in addition to morphologically ergative languages (e.g. Walpiri, Niuean), there are also socalled 'syntactically ergative languages': both those which display ergative A-bar properties (i.e. ban A-bar extraction of transitive subjects) but accusative Aproperties (Tagalog, Chukchi), and those which display ergative A- and A-bar properties, the so-called high absolutive languages, which fail to license absolutive objects in non-finite clauses - Q'anjob'al, Seediq (see Aldridge 2004, 2008, Coon et al. 2015, Deal 2015, Legate 2008, 2012, 2014, Sheehan 2015b). The contrast between high absolutive Q'anjob'al and low absolutive Chol (both Mayan languages) can be seen in: (i) the location of absolutive morphology on the aspect marker or verb respectively (4)-(5), (ii) the availability of absolutive

\footnotetext{
${ }^{2}$ As an anonymous reviewer points out, Sigurðsson (1991) also shows that (3) becomes grammatical where the dative is licensed as an expletive associate in base position. For our purposes what is relevant is that there are restrictions on datives so that dative does not itself serve a licensing function. Sigurðsson (1991) does in fact assume that examples like (2) involve ECM (see also Sigurðsson 2012 who calls it quirky raising to object/ECM). As the same reviewer notes, further issues arise in Icelandic from evidence that PRO also bears case (something that we return to below). We thank the reviewer for asking us to clarify this point.
} 
case in aspectless nominalisations (6)-(7) and (iii) the possibility of A-bar extraction of the transitive ergative subject (8) (all data from Coon et al. 2014, see also Tada 1993). Note that for the external argument of a transitive predicate to be A-bar extracted in Q'anjob'al the verb must be bear either antipassive or agent focus morphology:

(4) Q'anjob'al (High ABS) (Coon et al. 2014: 190)
a. Max-ach y-il-a'.
ASP-2ABS 3ERG-see-TV
'She saw you.'
b. Max-ach oq'-i.
ASP-2ABS cry-ITV
'You cried.'

(5) Chol (Low ABS) (Coon et al. 2014: 190)
a. Tyi y-il-ä-yety.
ASP 3ERG-see-TV-2ABS
'She saw you.'
b. Tyi uk'-i-yety.
ASP cry-ITV-2ABS
'You cried.'

(6) Q'anjob'al (High ABS): no ABS in nominalisations (Coon et al. 2014: 196)
a. [Chin y-il ${ }^{*}$ uj ix Malin] ASP be.able.to 1ABS 3ERG-see CLF Maria Intended: 'Maria can see me.'
b. Chi uj [hin y-il-on[-i]
ASP be.able.to 1ABS 3ERG-see-AF-ITV CLF Maria
'Maria can see me.'

(7) Chol (Low ABS): ABS on 0 in nominalisations (Coon et al. 2014: 202)

Mejl [i-k'el-oñ]

be.able.to 3ERG-see-1ABS

'She can see me.'

(8) Q'anjob'al (syntactic ergativity) (Coon et al. 2014: 193, 215)
a. ${ }^{*}$ Maktxel $_{1} \quad \max \quad \mathrm{y}$-il[-a] $\mathrm{t}_{1} \quad$ ix ix
who ASP 3ERG-see-TV CLF woman
Intended 'Who saw the woman?'
b. Maktxel $_{i}$ max-ach il-on- $i \quad t_{i}$ ? who ASP-2ABS see-AF-ITV
'Who saw you?'

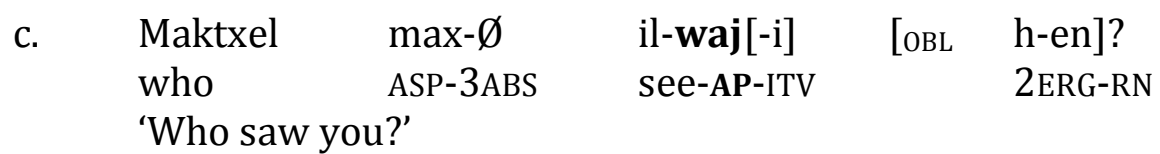


The crucial point here from our perspective is the assumption, argued for by Coon et al, that in Q'anjob'al the object fails to be licensed in Aspectless nominalisations because absolutive Case is not available. The analysis proposed by Coon et al. (2014) for this is that absolutive agreement is the spell out of Agree with v in Chol and Agree with INFL in Q'anjob'al. Once again, then, this seems to highlight that while case/agreement and nominal licensing are not intrinsically linked (i.e. we can find mismatches), (i) there is some notion of nominal licensing which is common to many languages and (ii) this can be realized via morphological case (though it need not be). In Q'anjob'al, the relationship between agreement and licensing is transparent: ABS agreement is always the spell out of Agree with INFL, whereas in Chol it is opaque, as ABS agreement can be the spell out of Agree with either INFL (in intransitive contexts) or $\mathrm{v}$ (in transitive contexts).

This (imperfect) connection between Vergnaud licensing and morphological case/agreement in some languages has heavily influenced generative theory. Chomsky $(1995,2000,2001)$ translates the Government and Binding Case Filter into a system in which uninterpretable Case features on DPs must be deleted for convergence. According to the Uniformity Principle, the default assumption is that this should be a universal property of natural language syntax, with what is parameterized being only how languages realize these syntactic dependencies in their morphology (Chomsky 2001). Some languages realize both the [uCase] feature (as morphological case) and the verbal [uPhi] feature (as agreement), others realise only one or the other, and many languages realise neither. In other languages, like Icelandic, case morphology and licensing function semi-autonomously, but the feature relevant to Vergnaud licensing is still standardly assumed to be [uCase].

The original motivation for Vergnaud licensing is centred on the grammaticality/ungrammaticality of overt subject DPs in finite vs. non-finite clauses and the distribution of adpositions, with the latter assumed to reveal contexts where structural licensing is unavailable. In the course of more than four decades of research, however, many other surface properties have been attributed to Vergnaud licensing. In what follows we summarise nine potential diagnostics for nominal licensing, before applying these diagnostics to a variety of unrelated languages in order to assess its cross-linguistic status.

The diagnostics we take to be descriptive in nature, and we see them as a potential cluster of associated properties, based on the behavior of English and some other Indo-European languages. We use them to test the extent to which properties cluster together in languages lacking morphological case. ${ }^{3}$ To the extent that some of them do, we assume that there must be an explanation for this. The current study is thus intended to form the basis of a more informed, theoretically-oriented discussion of nominal licensing in a broader range of languages than is usual.

While some of the diagnostics we discuss are widely assumed (i, ii, iii, vi, viii, ix), others are less uniformly accepted (iv, v, vii). We are nonetheless initially maximally inclusive here for methodological reasons, though we indicate some

\footnotetext{
${ }^{3}$ In the domain of Case Theory the distinction between description and theory is difficult to make, as the 'theory' itself is little more than an abstract description of the facts. No deep reason has ever been offered, to the best of our knowledge, as to why $\mathrm{D} / \mathrm{N}$ requires licensing whereas $\mathrm{T} / \mathrm{V}$ does not, nor why $\mathrm{P}$ and $\mathrm{T}$ should serve to license $\mathrm{N}$ whereas $\mathrm{D}$ does not.
} 
of the controversial issues for each diagnostic as we progress. The diagnostics are as follows:

i. $\quad$ Non-finite clauses. Assuming that Vergnaud licensing as subject is dependent on some (language-specific) aspect of 'finiteness' (agreement Raposo 1987, Chomsky 1995, 2001, Quicoli 1996; tense - Haegeman 1985, Iatridou 1993, Varlokosta 1994, Martin 1996, Alexiadou \& Anagnostopoulou 2002, Pesetsky \& Torrego 2001, 2004; clausal (in)dependence - Sitaridou 2006; aspect - Adger and Harbour 2007, Coon 2013, Coon et al. 2015; see also Cowper 2002, Landau 2004 and Nikolaeva 2007 on the broader notion of finiteness), if a language fails to permit overt referential DP subjects in a coherent class of independently diagnosable non-finite (i.e. agreementless/tenseless/aspectless) clauses, then the language has Vergnaud licensing. If it shows no such restriction then it may lack Vergnaud licensing. We examine three such non-finite environments: ${ }^{4}$

a. complements of raising verbs;

*It seems [John to eat pancakes].

b. complements of control verbs without Exceptional Case Marking or an overt complementiser;

(10) *We hope [John to eat pancakes].

c. and sentential subjects without an overt complementiser.

(11) *[John to eat pancakes] would be good.

A fourth environment are non-finite adjunct clauses, such as * We got some money [John to buy pancakes]'. We have not included these since it is generally more difficult to establish the (non-)finite nature of adjunct clauses (see Haspelmath \& König 1995). We do not, however, expect these to behave differently from complement clauses with respect to subject licensing.

ii. $\quad$ Agreement. In a language with Vergnaud licensing in which morphology tracks the former, all else being equal, high agreement will track the grammatical function of subject (see Pesetsky \& Torrego 2001), ${ }^{5}$ so

\footnotetext{
${ }^{4}$ This diagnostic faces certain well-known challenges which we return to below (see Landau 2006).

${ }^{5}$ Baker (2008) identifies 19 languages in which AgrS is not dependent on (morphological) case. Of these, 12 are ergative (where agreement on $\mathrm{T}$ is expected to be with the unmarked or absolutive argument, not just the nominative), 4 have neutral alignment, 1 is tripartite (Nez Perce, which has been argued to be ergative in its syntax (Müller \& Thomas 2014)), and 1 is a marked nominative system (Maricopa). This leaves Imbabura Quechua as the unexpected accusative language where AgrS is independent of nominative case, and interestingly it also shows hyperagreement. This seems like an interesting candidate for a language without Vergnaud licensing. The morphological accusative marking in this language is perhaps not tied to syntactic licensing (but rather functions as differential marking for topicality/animacy/definiteness). This remains an issue for further research.
} 
(modulo quirky subjects) the presence of non-agreeing 'subject' DPs suggests the absence of Vergnaud licensing: unless there is some other licensing mechanism available for such subjects they remain unlicensed. ${ }^{6}$ For example, in Standard English, the verb agrees with nominative subjects, even if they are in a postverbal position. As we shall see below, this is not true for all languages. ${ }^{7}$

(12) a. In the garden were/*was standing three unicorns.

b. There seem/??seems to be three unicorns in the garden.

iii. Activity. According to the Activity Condition (Chomsky 2000, 2001), a DP cannot be targeted for $\phi$-agreement or A-movement once has been Vergnaud licensed. If the language permits movement from a Vergnaudlicensed position to another A-position, this 'hyperactive' movement suggest that the language lacks nominal licensing (cf. Carstens 2011). In English, for example, raising can take place only from non-finite complements (13b) as finite complements are subject licensing domains (13a).

(13) a.*Theyi seem [(that) $t_{i}$ are sorry].

b. They $y_{i}$ seem [ $t_{i}$ to be sorry].

iv. Passive agents. If the agent-DP of a passive can be realised without special morphology or some alternative licensing mechanism such as a preposition (14), then Vergnaud licensing may not play a role in the language. Likewise, if the language has only a short passive and disallows the overt expression of the demoted external argument, then this indicates (indirectly) that the language has Vergnaud licensing, assuming the problem here is the lack of a licenser for the demoted agent-DP (see Roberts \& Sheehan 2015).

(14) The last biscuit was eaten *(by) me.

v. Grammatical function-based asymmetry. If a language has subject/object asymmetries (e.g. extraction asymmetries, that-trace effects) that cannot be accounted for by appealing to (a) information structure or (b) thetarole asymmetries, then these asymmetries may be due to Vergnaud licensing (Pesetsky \& Torrego 2001, 2004). If a language lacks such asymmetries, Vergnaud licensing may or may not play a role. ${ }^{89}$

\footnotetext{
${ }^{6}$ In a language like Icelandic, Vergnaud licensing and case are not aligned so there is indeed an alternative licensing mechanism (see Sigurðsson 2012).

${ }^{7}$ An immediate question arises in languages such as French with it-type expletives which occur with associates and yet trigger $3 \mathrm{SG}$ agreement on the verb.

(i) il est venu des enfants hier.

It is come some children yesterday

We assume, as is standard, that in such cases there is an additional licensing mechanism of some kind available (see Belletti 1988).

${ }^{8}$ An anonymous reviewer asks about the status of Romance languages, which may lack that-trace effects because subject extraction proceeds from a postverbal position (Rizzi 1982). As he/she notes, this suggests that that-trace effects actually diagnose a structural subject position rather than the
} 
(15) a.*Whoido you think [that $t_{i}$ left]?

b. *Who do you think [that $t_{\mathrm{i}}$ likes John]?

c. Who do you think [that John likes $t_{i}$ ]?

Note that the existence of syntactic ergativity (discussed above) whereby such a restriction applies only to (transitive) ergative subjects, is strong evidence that the relevant notion here is related to Vergnaud licensing, which can in turn be reflected in surface morphology. ${ }^{10}$

vi. Morphology. If a language has morphological case which does not track theta-roles or information structure then it may also have Vergnaud licensing, but not vice versa. At the heart of this is the observation that in English, as in many other languages, there is no stable correspondence between the morphological cases (Nominative, Accusative) and thetaroles (Agent, Theme etc.). ${ }^{11}$

(16) a. She likes her.

b. She believes [her to like John].

c. [For her to like her] would be unlikely.

d. She is liked by her students.

vii. Anaphors. According to the dominant generative analysis, it is not possible to agree with anaphors (Rizzi 1990, Woolford 1999). It follows that if a language has subject anaphors it cannot have subject agreement and by implication the subject cannot be Vergnaud-licensed, showing the absence of nominal licensing. Conversely, if a language displays a ban on subject anaphors, it follows that the language in question has subject agreement and hence presumably has Vergnaud licensing. English falls under this account as a language which has (limited) subject verb agreement and hence bans subject anaphors. Crucial in this regard is the contrast

presence of Case per se. We would agree that the lack of that-trace effects indicates nothing about the presence/absence of Case for the reasons the reviewer points out. On the question of what that-trace effects actually diagnose, it seems that the notion of subject position and indeed of grammatical functions more generally is intricately connected to nominal licensing, though this may not ultimately be attributable to Case or case (see our discussion in section 4.3). Note that if grammatical functions reduce to Case then the kinds of subject/object asymmetries discussed for Mandarin can also be taken as indirect evidence for Case in that language (see Huang 1984, Miyagawa 2010: ch2).

${ }^{9}$ It has also been claimed that that-trace effects are not due to Case/grammatical functions at all but rather are a prosodic effect (Kandybowicz 2006).

${ }^{10}$ Though there are many different accounts of syntactic ergativity in the literature, many explicitly relate the effect to Case-assignment hence to Vergnaud licensing in our terms. For example, for Coon et al. (2015), the effect is due to movement of the object past the subject in order to render it visible to T/Asp, and, for Erlewine (2016), syntactic ergativity and that-trace effects result from anti-locality, where it is Case-assignment which ensures that in accustaive languages all subjects occupy spec TP whereas in ergative languages only transitive subjects do. See Douglas \& Sheehan (2016) for a discussion of these approaches and evidence that both are required for different Mayan languages.

${ }^{11}$ As an anonymous reviewer notes, this diagnostic is problematic if we assume the existence of dependent case and this kind of case is not connected to licensing in any way. While Marantz (1991) first conceived of dependent case in a post-syntactic terms, however, Baker (2015) argues that it is syntactic and thus serves a licensing function. Nonetheless, we question to reliability of this below as a diagnostic for Vergnaud licensing. 
between (17c-d), which shows that subjects can contain non-nominative anaphors, so this is not a fact about binding domains: ${ }^{12}$

(17) a. John washed himself.

b. John believes himself to be intelligent.

c. *John believes that himself is intelligent.

d. John thinks that [a picture of himself] should be attached to his CV.

viii. Assigners. Assuming that not all categories are licensers, if DPs in a given language pattern differently when they are the arguments of a coherent class of categories (i.e. verb/preposition as opposed to adjective/noun) then the language has Vergnaud licensing.

(18) a. John is frightened $*$ (of) ghosts.

b. John's fear *(of) ghosts.

c. John fears $(*$ of $)$ ghosts.

ix. Assignees. Assuming that DPs need licensing but CPs do not (Stowell 1981), if DPs pattern differently from CPs in a given language in terms of their distribution/marking, then the language has Vergnaud licensing. If there is no such difference then either the language lacks Vergnaud licensing, or CPs also require licensing.

(19) a. John fears [cP that monsters exist].

b. John's fear [cP that monsters exist].

c. John fears [DP monsters].

d. John's fear of [DP monsters].

This list of nine diagnostics is by no means intended to be exhaustive, but as it is representative of the evidence in favour of abstract Case in a language like English, it serves as a starting point to examine the cross-linguistic status of Vergnaud licensing. Although some of these diagnostics are fairly controversial (see the footnotes and further discussion in section 6.2), the relevant question here is whether these properties cluster together in a wider sample of languages. If they do (as we argue in this paper), then we submit that a unified account should be preferable as it is more parsimonious (see also Diercks 2012), though we acknowledge that Case Theory as it stands is somewhat deficient as an explanation for reasons to which we return below.

\footnotetext{
${ }^{12}$ An anonymous reviewer raises some objections to this analysis, citing work by Postal 1971, Pollard \& Sag 1992, Reinhart and Reuland 1993 on picture nouns regarding the contrast between (17c-d). We would agree with these objections and indeed, as we shall see below, the results in our six languages suggest that the availability of subject anaphors cannot be attributed to Case (see also Sundaresan 2015 for the same point). We include the diagnostic here because it is widely assumed in the generative literature.
} 


\section{Parameterised nominal licensing in Bantu: Luganda vs. Makhuwa}

New data from Luganda (spoken in Uganda) show that this Bantu language patterns with the languages that Diercks (2012) labels as 'Caseless' and which lack Vergnaud licensing in our terms, whereas the data for Makhuwa (spoken in Mozambique) show the opposite setting on most of our diagnostics (Van der Wal 2015a). This is summarised in Table 1 . We present the evidence for the four relevant diagnostics in the remainder of this section.

\begin{tabular}{|l|l|l|}
\hline & Makhuwa & Luganda \\
\hline 1. Non-finite clauses & + & - \\
\hline 2. Agreement & + & - \\
\hline 3. Activity & + & - \\
\hline 4. Passive agent & + & - \\
\hline
\end{tabular}

Table 1: Case diagnostics (+ evidence of Case, - evidence of no Case)

\subsection{DP subject of a non-finite clause}

Assuming that only finite clauses are subject-licensing domains, a restriction on the presence of overt referential DP subjects in non-finite clauses is indicative of the presence of Vergnaud licensing, whereas the absence of such a restriction argues for its absence. ${ }^{13}$ As mentioned above, we can test this restriction where clauses function as the complements of raising/control verbs and where they function as subjects.

Luganda freely allows overt subjects in non-finite (agreementless) complement clauses of raising verbs (20), as well as non-finite complements of control predicates (21), and overt DP subjects are grammatical in non-finite subject clauses (22), like the Bantu languages argued to lack Case by Diercks (2012) (Digo, Swahili and Lubukusu). ${ }^{14}$

$$
\text { Ki-kkiriz-ibwa [Tenhwa okutambul-ira mu-mazzi]? }
$$

7SM-allow-PASS 1.Tenhwa 15.walk-APPL 18-6.water

'Is it allowed (for) Tenhwa to walk in the water?'

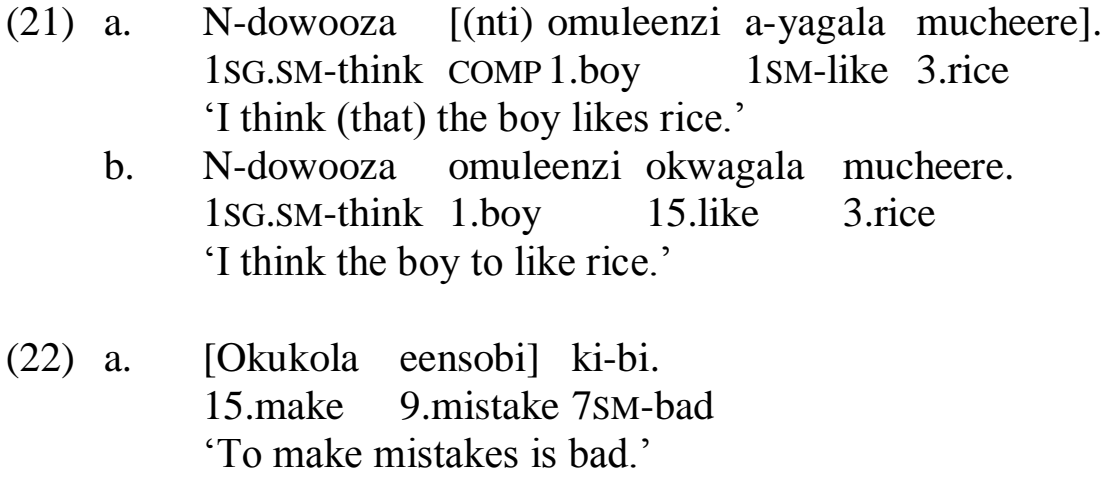

\footnotetext{
${ }^{13}$ We refer to overt referential DPs here as it has been shown that in a number of languages, overt focused pronominals are licensed in control contexts, so the opposition is not simply between overt and covert subjects (see Szabolszi 2009, Barbosa 2009).

${ }^{14}$ Infinitives in most Bantu languages are part of the noun class system and are here glossed as class 15.
} 
b. [Joel okukola eensobi] ki-bi.

1.Joel 15.make 9.mistake 7SM-bad

'(For) Joel to make mistakes is bad.'

Makhuwa, however, patterns differently, failing to permit overt DP subjects in such contexts (Van der Wal 2015a). Makhuwa appears to lack raising-to-subject verbs, which leaves two environments to test. First, non-finite complements to control predicates cannot contain an overt subject (23a,b). Instead, a subjunctive (optative) needs to be used (23c).
(23) a.
Ki-m-phéélá
waapeyá.
1SG.SM-PRES.CJ-want 15.cook
'I want to cook.'
b. *Ki-m-phéélá [Amína waápéya nráma].
1SG.SM-PRES.CJ-want 1.Amina15.cook 3.rice
int. 'I want Amina to cook rice.'
c. Ki-m-phéélá [Amína a-apéy-e nráma]. ${ }^{15}$
1SG.SM-PRES.CJ-want 1.Amina1SM-cook-OPT 3.rice
'I want Amina to cook rice.' (Van der Wal 2015a: 120)

Second, what seems to be an overt subject DP of a non-finite (agreementless)

clausal subject is necessarily interpreted as a vocative followed by a pause (24b), that is, non-finite clausal subjects cannot themselves contain overt subjects, arguing for the presence of Case in Makhuwa.

(24) (stimulus: (for) Maria to eat rice would be good)

[Makhuwa]
a. María * (,) ócá nráma w-aánáa-réera.
1.Maria 15.eat 3.rice 15SM-IMPF-be.good
'Maria, to eat rice would be good.'
b. W-aaní-réera Maríya ó-c-e.
SM-IMPF-be.good 1.Maria 1SM-eat-OPT
'It would be good if Maria ate.'
c. Óca nráma w-aánáa-réera.
15.eat 3.rice SM-IMPF-be.good
'To eat rice would be good.' (Van der Wal 2015a: 124)

This test thus diagnoses Luganda as a language where DPs do not need to be

Vergnaud licensed, whereas Makhuwa DPs are shown to require Vergnaud licensing.

\subsection{Subject agreement}

In Luganda, the "subject marker" can agree with a preverbal subject, as in (25a), or with a preverbal locative when the logical subject occurs postverbally, as in (25b).

\footnotetext{
${ }^{15}$ For evidence that 'Amina' is in the lower clause, see Van der Wal (2015a).
} 
(25) a. Omuwalaa-beera mu-nyuumba eno.

[Luganda]

1.girl 1SM-live18-9.house 9.DEM

'A/the girl lives in this house.'

b. Mu-nyúúmb' eeyó mú-bééra-mú omuwála.

18-9.house 9.DEM 18SM-live-18LOC 1.girl

'In that house lives a/the girl.'16

The postverbal logical subject omuwala 'girl' in the locative inversion

construction (25b) is not licensed by agreement on the verb, nor does it behave like an object. As Diercks (2012) summarises, there have been many proposals regarding how to account for this lack of licensing, but he suggests that the simplest and most elegant solution is to abandon Case licensing for these languages: the postverbal DP simply does not need to be Vergnaud licensed. The agreement on the verb has been argued to be more sensitive either to position (Baker 2008 proposes that Agree in Bantu is always upward) or to information structure (Morimoto 2006, 2007 proposes that this is topic agreement rather than subject agreement). Either way, the crucial point is that agreement does not track the grammatical function of subject in these languages, hence cannot be a reflex of Vergnaud licensing.

In Makhuwa, on the other hand, the verb always agrees with the subject regardless of whether the latter occupies a pre- or postverbal position, as shown in (26). We take this to be the result of agreement tracking licensing in this language (see more detailed discussion in Van der Wal 2015a).

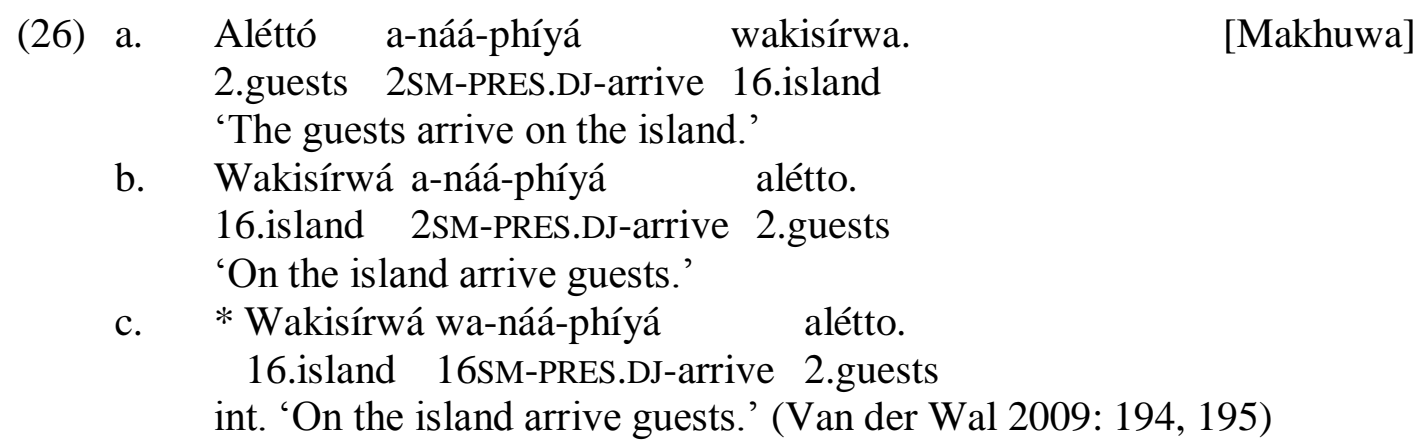

This diagnostic again illustrates the difference between Luganda, which does not require its DPs to be licensed, and Makhuwa which does.

\subsection{Activity}

According to Chomsky $(2000,2001)$ uninterpretable Case features serve to render DPs active for $\phi$-agreement (the Activity Condition). Upon Agree, a DP's uninterpretable Case feature is deleted and the DP thus becomes unavailable for further Agree relations of this kind. The empirical prediction of this account is that agreement with, and A-movement of, a Vergaud-licensed DP should be blocked. It follows that if a language permits DPs to be active even after they

\footnotetext{
${ }^{16}$ Note that the postverbal logical subject is not restricted in definiteness and can thus not be claimed to have partitive case (à la Belletti 1988):

i. Munyumba eyo mubeeramu muwala wange.

'In that house lives my daughter.'
} 
have been licensed, as evidenced by 'hyperagreement' and 'hyperraising', then the implication is that activity does not apply or at least that abstract Case does not function as an activator for DPs, which is consistent with a lack of abstract Case, or, in our terms, the irrelevance of Vergnaud licensing. ${ }^{17,18}$

In Luganda, hyperactivity is visible in complex tenses that have two inflected verbs which both agree with the subject as in (27a), and in hyperraising, where both the raising verb and the lower verb agree with the raised subject, as in (27b).

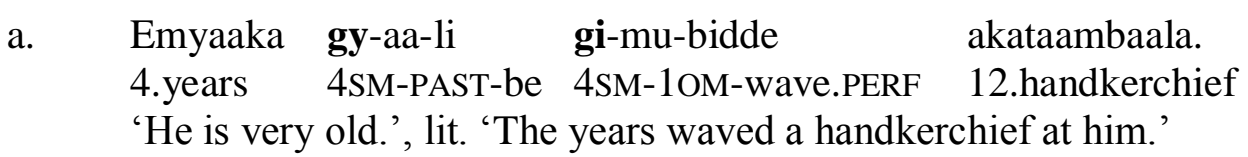

b. Abaana ba-labika ba-beera mu-nyuumba eno. [Luganda] 2.children 2sM-seem 2sM-live 18-9.house 9.DEM '(The) children seem to live in this house.' lit. '(The) children seem live in this house.'

The possibility of idioms, as per (27a), shows that this is movement rather than base generation and concord (see also Carstens and Diercks 2013 show for Lubukusu and Lusaamia). If Luganda has Vergnaud licensing then this Amovement from a licensed position would be unexpected.

Makhuwa, at first sight, appears to show multiple agreement in complex tenses as well, as shown in (28).
Vánóki-hááná
ki-thel-áka.
[Makhuwa]
PTCL 1SG.SM-have 1SG.SM-marry-DUR
'Now I have to marry.' (Van der Wal 2015a: 127)

However, it can be shown that this is not a hyperactive construction. First, there are no real raising predicates in Makhuwa, second, the durative form never licenses an overt referential subject, and third, the lower verb in the durative form (kithelaka) can be shown to be a non-finite agreeing participle-like verb form (see the concord analysis in Henderson 2006). Van der Wal (2015a) discusses the correlates of finiteness in Makhuwa, concluding that it is not dependent on $\phi$ completeness or (semantic) tense, but rather on independent sentencehood. The lower dependent verb form (the durative kithelaka in (28)) does not show evidence of independent sentencehood, and is therefore not a finite verb, suggesting that there is no movement to multiple Case positions, hence no hyperagreement.

The same conclusion is reached: DPs must be Vergnaud licensed in Makhuwa but not in Luganda.

\footnotetext{
${ }^{17}$ See Carstens (2011) for the proposal that a different kind of feature can count for activity (e.g. [uGender]).

${ }^{18}$ It is worth noting that there are languages that otherwise appear to have Case which display hyperactivity/hyperraising (e.g. Brazilian Portuguese). Ferreira (2004) proposes an analysis of this based on the proposal that finite $\mathrm{T}$ is phi-deficient and so can fail to be a licensor.
} 


\subsection{Passive agent}

In a typical passive, the agent is demoted from subject position. It is still part of the thematic structure, but it is not licensed by the verb and hence needs a preposition ('by' in English) to appear overtly. Thus, if a language allows the agent DP to surface without any such licensing, this is indicative of the lack of Vergnaud licensing, and vice versa. As expected by now, the two languages, once again, behave differently.

Luganda allows the overt expression of the agent without any preposition or licensing 'linker', whereas in Makhuwa a preposition is required:

$$
\begin{array}{lll}
\text { Abaana } & \text { ba-a-soma } & \text { ekitabo. } \\
\text { 2.children } & \text { 2SM-PST-read } & \text { 7.book } \\
\text { 'The children read a book.' }
\end{array}
$$

b. Ekitabo ky-aa-som-ebwa abaana.
7.book 7SM-PST-read-PASS 2.children
'The book was read (by) the children.'

$$
\begin{array}{ll}
\text { Íi, koo-vár-íya } & * \text { (ni) khwátte! } \\
\text { ii 1SG.SM.PERF.DJ-grab-PASS } & \text { by } 1 . \text { fox } \\
\text { 'Ii, I am caught by the fox!' } &
\end{array}
$$

[Makhuwa]

One could think that the function of the preposition is not only to license the agent, but to introduce the agent in the theta-structure of the verb, therefore not necessarily telling us anything about Case. However, the felicity of agentoriented adverbs and purpose clauses in the Makhuwa passive, as presented in Van der Wal (2015a), show that the agent argument is still present in the passive in Makhuwa even when not overtly expressed, and so the problem is with its overt expression. This diagnostic is not discussed by Diercks (2012), but a cursory glance suggests that at least some of the languages he discusses apparently pattern with Makhuwa rather than Luganda on this diagnostic, unexpectedly. The prediction is that in Lubukusu the agent-introducing preposition has a different non-licensing function unlike that which it has in Makhuwa. Further investigation is needed to ascertain whether this is the case.

The careful reader will note that we have only actually discussed four of our nine diagnostics here. The reason for this, as will become clear below, is that diagnostic 5 fails to be revealing in these languages, for reasons we outline in section 4.3. Diagnostics six to nine we argue to be problematic as cross-linguistic diagnostics of Vergnaud licensing, both in Bantu and beyond. We reserve this discussion until section 5 , when we discuss all six of our languages together.

In conclusion, the Bantu languages Luganda and Makhuwa clearly pattern differently with respect to the above diagnostics, suggesting that DPs do not need to be Vergnaud-licensed in Luganda, whereas they do in Makhuwa. This is a very interesting result as it suggests that: (i) there is a cluster of surface properties associated with nominal licensing which pattern together; (ii) not all caseless languages pattern alike with respect to nominal licensing and (iii) even closely related languages even pattern differently. Diercks' proposed analysis is that the [uCase] feature is simply missing from DPs in languages like Lubukusu and Zulu (and Luganda) so that no licensing is required. Given the rich 
agreement morphology in Luganda and Makhuwa, moreover, it is easy to see how this featural difference could be acquired by a child. The very diagnostics discussed above would all lead the child to post [uCase] in Makhuwa but potentially not in Luganda.

Two interesting follow-up questions can now be asked: First, is the appearance of DPs unrestricted in a language without Vergnaud licensing (like Luganda)? Second, what happens in a language which lacks inflection altogether (i.e. neither case nor agreement): do we find the same parameterization amongst analytic languages? The first question is addressed in section 6.1 and the second question forms the core of our research in the next section.

\section{Vergnaud licensing in languages without morphological case or agreement}

To assess the status of Vergnaud licensing languages without agreement or case (on full DPs), we now apply the diagnostics to four analytic languages: Thai (TaiKadai, spoken in Thailand), Jamaican Creole (English lexifier Creole, spoken in Jamaica), Yoruba (Niger-Kordofanian, Benue-Congo, spoken in Nigeria), and Mandarin (Sino-Tibetan, Chinese, spoken in China). These languages were chosen as four unrelated but typologically similar languages for which we had access to native speaker informants. We used a uniform questionnaire in our elicitation with native speakers, and combined this with a survey of the available literature, grammars of the various languages and consultation with language specialists.

Of the nine diagnostics presented in section 2, the second is, of course, not applicable to these languages as they uniformly lack verbal agreement and the final four turn out to be unreliable, as we shall see below. This leaves us with four (reliable) diagnostics to test the status of Vergnaud licensing in these languages: non-finite clauses, activity, GF-based asymmetries and licensing of the passive agent. We discuss these in detail in the following subsections - Table 2 summarises our results.

\begin{tabular}{|l|l|l|l|l|}
\hline & Mandarin & Thai & Yoruba & JC \\
\hline 1. Non-finite clauses & + & + & + & + \\
\hline 2. Agreement & n.a. & n.a. & n.a. & n.a. \\
\hline 3. Activity & + & + & + & + \\
\hline 4. Passive agent & n.a. & n.a. & n.a. & + \\
\hline 5. GF-based asymmetry & 0 & 0 & + & + \\
\hline
\end{tabular}

Table 2: Case diagnostics for analytical languages

(where $+=$ evidence of Case, $-=$ evidence of no Case, $0=$ compatible with either, n.a. $=$ test cannot be applied, $?=$ no data or unclear)

As is obvious from this table, only Jamaican Creole passes all of the relevant diagnostics, but all of the other languages pass at least two of them. Crucially, to the extent that they are applicable and informative, the diagnostics pattern together, suggesting that something limits the distribution of over referential subjects in all these languages. 


\subsection{DP subject of a non-finite clause}

As mentioned above, assuming that non-finite $\mathrm{T}$ does not have the ability to license subject DPs, if overt referential subject DPs are permitted in non-finite clauses, then this points to the absence of Vergnaud licensing, and vice versa.

A significant methodological obstacle arises in analytic languages as the distinction between finite and non-finite clauses in these languages is not straightforward. Even if there is a class of contexts which fail to license overt referential DP subjects, this cannot be taken as evidence for Case in the absence of some independent diagnostic for 'non-finiteness' lest the argument become circular. Fortunately, in all languages independent diagnostics for non-finiteness are available. Thai and Mandarin lack an overt marker of non-finiteness, but have tense/aspect markers which are restricted to finite clauses. The Thai irrealis marker $c \grave{a}$ ? and perfective marker laew are not possible in non-finite clauses (Jenks 2006) nor are the Mandarin modals hui 'will', neng 'can', keyi 'may' or yinggai 'should' (Huang 1989). Other potential finiteness diagnostics in Mandarin include the distribution/scope of the aspectual particles $l e$ and zai and the availability of object shift (see Huang 1982, 1989, Li 1985, 1990, Tang 1990, Tang 2000, Tsai 1995, Paul 2002, Lin 2011, but also $\mathrm{Hu}, \mathrm{Pan}$, and $\mathrm{Xu} 2001$ for some objections). Yoruba has the non-finite marker láti which appears in the $\mathrm{T}$ position and which is incompatible with the finite complementiser pé (31), and Jamaican Creole uses the non-finite marker fi versus finite se or dat.
a.
Ó burú láti șe
àșìse.
it bad to make mistake
'It's bad to make mistakes.'
b. Ó jọ pé Dọ̀tun nífè̀é Sídí it resemble that Dotun love Sidi 'It seems that Dotun loves Sidi.'

[Yoruba]

Once the finite/non-finite distinction is controlled for in this independent way, all four remaining languages fail to license overt DPs as the subjects of non-finite clauses, providing evidence for the abstract Case property.

In Yoruba, non-finite clauses cannot host overt DP subjects. We have not been able to find a genuine raising predicate in Yoruba. Predicates such as jo 'resemble/seem' take finite complements (as indicated by the finite complementiser and the impossibility of the non-finite marker láti) and occur either with an expletive subject (25a) or in a copy-raising construction (32b), to which we return in section 4.2 :
a. Ó jọ pé Dọ̀tun nífẹ̀ẹ Sídí. it resemble that Dotun love Sidi 'It seems that Dotun loves Sidi.'
b. Dọ̀tun jọ pé *(ó) nífẹe sí Sídí. Dotun resemble that $3 \mathrm{SG}$ love Sidi 'Dotun seems like he loves Sidi.'
a. *ó jọ
It resemble
Dọ̀tun láti
nífèè Sídí.

Dotun to love Sidi

[Yoruba] 
$\begin{array}{lll}\text { b. } \quad \text { Dọ̀tun jọ } & \text { láti nífèe Sídí. } \\ \text { Dotun resemble to love Sidi }\end{array}$

We nonetheless find evidence that overt referential DPs are not licensed in nonfinite clauses from the complements of control predicates. In control contexts, overt DPs are only possible if the preposition fún is present (superficially, at least, similarly to English 'for'), and even then they are very marginal for one of our two informants. Note crucially that fún is not required where the subject of the clause is PRO:
a. A ní
ìrètí láti
dé ní
àlàáfíà.
we have
hope to
arrive in
peace
[Yoruba]
'We hope to arrive safely.'
b. (?)A ní ìrètí *(fún) bàbá láti dé ní àlàáfíà. we have hope for father to arrive in peace
'We hope for father to arrive safely.'

Finite complements are also permitted in such contexts with overt DP subjects:

(35) A ní ìrètí pé bàbá dé ní àlàáfíà. we have hope that father arrives in peace 'We hope that father arrives safely.'

Finally, non-finite subject clauses, which are obligatorily extraposed, also cannot host an overt DP subject unless the preposition fún is present. Again, fún is only required where the clause has an overt referential subject:

$$
\begin{aligned}
& \text { a. Ó burú láti șe àșìse. } \\
& \text { it bad to make mistake } \\
& \text { 'It is bad to make mistakes.' }
\end{aligned}
$$
b. Ó jẹ́ ohun àjèjì *(fún) Dọ̀tun láti șe àșișe. it be thing strange for Dotun to make mistake 'It's a strange thing for Dotun to make mistakes.'

Much like Yoruba and English, Jamaican Creole also shows a ban on overt subjects in non-finite clauses. Jamaican Creole again has copy-raising rather than true raising (see section 4.2), but overt referential subjects in control contexts (38) are ungrammatical in the absence of the non-finite complementiser fi. Where a non-finite clause functions as a subject, however, the complementiser $f i$ is required even where there is no overt subject, and so this context tells us nothing. ${ }^{19}$ Note that there are two distinct fis here, one which is presumably a T element, which follows the subject and is generally optional and the other which precedes the subject and looks superficially like English for and Yoruba fún:

\footnotetext{
${ }^{19}$ In this much it appears to pattern with the finite complementiser that in English, which is required where finite clauses function as non-complements (see Bošković and Lasnik 2003 for a possible analysis of this pattern).
} 
(37) a. It luk laik [(se) John lov Sara].

it look like that John love Sara

'It seems that John loves Sara.'

b. * It luk laik [(se) John fi lov Sara].

it look like that John INF love Sara

(*) 'It seems John to love Sara.'

c. $\quad *$ John luk laik fi lov Sara.

(38) a. Wi huop*(fi) papa (fi) kom sief.

1PL hope for fatherinF comesafe

'We hope for father to arrive safely.'

b. Wi huop [(se) papa kom sief].

1PL hope CoMP father comesafe

'We hope that father arrives safely.'

(39) a. [*(Fi)go mek mistiek] bad.

INF go makemistake bad

'To make mistakes is bad.'

b. [*(Fi)Joel (fi) go mek mistiek]strienj. for Joel INF go make mistake strange

'For Joel to make mistakes is strange.'

Thai again behaves similarly, though it lacks both (straightforward)

raising verbs and non-finite clausal subjects. Nonfinite clausal subjects are not accepted, even without overt referential subjects, as shown in (40).

(40) *[(Coo?eew) tham khaamphìt]pen sìn plæ̀æk. Joel make mistake COP thing strange

'(For) Joel to make mistakes is strange.'

Instead, non-finite subject clauses are rendered via a nominalisation (41a), (42), a relative clause (41b) or via two paratactic clauses (41c), even when there is no overt subject.
a. [Kaan tham
khaamphìt] pen sìn mâj dii. NOM make mistake
COP thing NEG good
'To make mistakes is bad.'
b. Coo?eew tham khaamphìt, sûn pen sìn plæ̀æk. Joel make mistake REL COP thing strange 'Joel made a mistake, which is strange.'
c. Coo?eew tham khaamphìt. Man pen sìn plæ̀æk. Joel make mistake it COP thingstrange 'Joel made a mistake. This/It is strange.'

[Thai]

(42) Kaan thîi fee chá?ná? keem cà? tham hâj mæ̂æ khว̌on lòn phə઼caj. NOM COMP Fay win game IRR CAUS BEN mother POSS 3SG.F be.pleased 'That Fay won the game would please her mother.' (stimulus: '(For) Fay to win the fame would please her mother') 
This leaves us with one Thai context in which to test for the possibility of overt subjects in non-finite clauses: the complements of control predicates. In this context, an overt referential DP can be the subject of a finite complement clause (43a), but a benefactive marker is required to license the overt subject of a nonfinite complement (43b). Without the benefactive marker, the sentence will be interpreted as two paratactic clauses (43c).

(43) a. Raw wăy [wăa phôj cà? maa thǔn jàan plòst.phaj]. 1PL hope COMP father IRR comearrive manner without.harm 'We hope that father arrives safely.'

b. Raw wăy hâj phôj maa thǔı jàan plòst.phaj. 1PL hope BEN father come arrive manner without.harm 'We hope for father to arrive safely.'

c. Raw wăn phôj maa thǔn jàan plòst.phaj. 1PL hope father come arrive manner without.harm 'We hope, father arrives safely.'

As mentioned above, we know that (43b) is non-finite and (43c) is finite, as the irrealis marker cà? $\left(\mathrm{b}^{\prime}, \mathrm{c}^{\prime}\right)$ and the perfect marker $l \bar{æ}: w\left(\mathrm{~b}^{\prime \prime}, \mathrm{c}^{\prime \prime}\right)$ can be added in the latter but not the former:

(43) b'. * Raw wăy hâj phôj cà? maa thụ̌ jàạ

[Thai]

1PL hope BEN father IRR come arrive manner

plòst.phaj.

without.harm

'We hope for father to arrive safely.'

b". ?? Raw wăy hâj phôj maa thǔn læe:w jàạ

1PL hope BEN father come arrive PERF manner

plòst.phaj

without.harm

'We hope for father to have arrived safely'

c'. Raw wăy | phôs cà? maa thǔn jàan plòst.phaj. 1PL hope father IRR comearrive manner without.harm 'We hope, father has arrived safely.'

c". Raw wăy | phôj maa thụ̌ lǣ:w jàạ plòjt.phaj. 1PL hope father come arrive PERF manner without.harm 'We hope, father has arrived safely.'

Mandarin Chinese paints a more complicated picture, which, however, we argue also provides potential evidence for Vergnaud licensing. The clausal complements of predicates such as sihu, hoaxing 'seem' and keneng 'likely/probably' can host overt referential subjects, but these are finite, as diagnosed by the possibility of them hosting modals (Huang 1989), and these morphemes do not in any case behave like verbs (J-W Lin 2010, Pan \& Paul 2014). 


$\begin{array}{llllll}\text { a. Sihu } & \text { John } & \text { (hui/neng/yinggai) } & \text { ai } & \text { Sara. } & \text { [Mandarin] } \\ & \text { Seem } & \text { John } & \text { will/can/should } & \text { love } & \text { Sara. } \\ \text { b. } & \text { John } & \text { sihu } & \text { (hui/neng/yinggai) } & \text { ai } & \text { Sara. } \\ & \text { John seem } & \text { will/can/should } & \text { love } & \text { Sara. }\end{array}$

As such, although (44a) looks superficially like the pattern observed in Luganda, it is actually wholly distinct. The grammaticality of what looks like hyperraising in (44b) presents a different challenge related to 'activity', which we return to in section 4.2. There is, however, a raising verb which appears to select non-finite complements. T-H Lin (2011) argues that the modal hui is itself a genuine raising predicate which takes a non-finite TP complement and requires obligatory raising of the embedded subject:

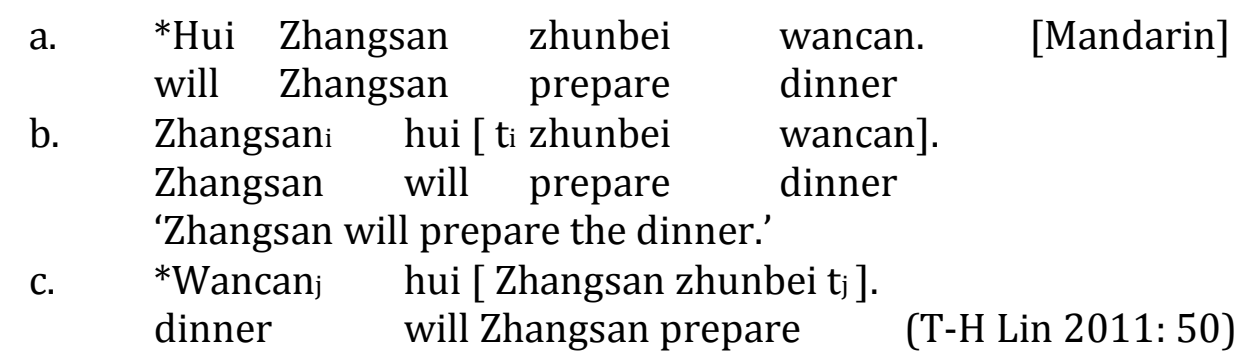

As mentioned above, further diagnostics for finiteness in Mandarin include the distribution/scope of the aspectual particles le and zai and the availability of object shift (see Huang 1982, 1989, Li 1990, Tang 1990, Tang 2000, Tsai 1995, Paul 2002, Lin 2011). Evidence that the complement in (45) is non-finite comes from its incompatibility with the perfect/inchoative particle le, as shown in (46) (from Lin 2011). Examples of this kind, then, support the idea that Mandarin has Case (though this is not Lin's conclusion): a DP subject cannot be licensed in a non-finite clause.
Zhangsan
hui qu Taibei $(* l e)$.
Zhangsan will go Taipei PERF
[Mandarin]
'Zhangsan will go to Taipei.'

With respect to the second non-finite context (control complements), Huang (1989) shows that Chinese has genuine instances of obligatory control where the clause (i) is non-finite (as evidenced by the ungrammaticality of modals) and (ii) cannot host an overt subject (see also Grano 2012 for a different analysis of these patterns).

$$
\begin{aligned}
& \text { Lisi shefa } \left.\quad{ }^{*} \text { ta }\right) \quad\left({ }^{*} \text { hui } /{ }^{*} \text { neng } /{ }^{*} \text { keyi } /{ }^{*} \text { zai }\right) \quad \text { lai. } \quad \text { [Mandarin] } \\
& \text { Lisi try he will/can/may/PROG come } \\
& \text { 'Lisi tried (*him) to come.' } \\
& \text { (Huang 1989: 189) }
\end{aligned}
$$

These kinds of complements can be contrasted with finite complements which can host both a modal and an overt referential subject:

$\begin{array}{llll}\text { (48) } & \text { Zhangsan } & \text { xiangxin } & \text { (ta) hui lai } \\ \text { Zhangsan } & \text { believe } & \text { he } & \text { will come }\end{array}$


It is a point of variation between English and Mandarin which matrix predicates take a non-finite obligatory control complement of the kind in (47) vs. a finite complement of the kind in (49). Consider examples (49)-(50), for example, which involve what would be obligatory control predicates in English, but which take finite complements in Mandarin, according to our diagnostics. ${ }^{20}$

Wo qidai/ xiwangZhangsan qu Taibei.

[Mandarin]
a. Wo qidai Zhangsan hui/neng qu Taibei. I expect Zhangsan will/can go Taipei 'I expect that Zhangsan will/can go to Taipei.'
b. Women xiwang Zhangsan hui/neng qu Taibei. We hope Zhangsan will/can go Taipei 'We hope that Zhangsan will/can go to Taipei.'

The same story holds in the third environment for our non-finite diagnostic. Mandarin subject clauses can also host overt DPs in the absence of any overt Case-marker:
a.
[Fan cuowu]
shi
is
'To make mistakes is bad.'
buhaode.
[Mandarin]
Make mistake
bad.
b. [Joel fan cuowu] shi qiguaide. Joel make mistake is strange
'(For) Joel to make a mistake is strange.'

But again, these sentential subjects can also host modals and so appear to be finite clauses, even where the subject is null and generic:
a. [Zhangsan hui/neng qu Taibei] shi qiguaide. [Mandarin] Zhangsan will/can go Taipei is strange 'It is strange that Zhangsan will/can go to Taipei.'
b. [Hui/neng qu Taibei] shi qiguaide. will/can go Taipei is strange 'It is strange that someone will/can go to Taipei.'

Taking into account these language-specific diagnostics for non-finiteness, there are no clear examples of overt DPs being hosted in the subject position of nonfinite clauses in Mandarin. ${ }^{21}$

\footnotetext{
${ }^{20}$ Grano (2012) shows that it is roughly the class of exhaustive control predicates in English which instantiate obligatory control in Mandarin. Partial control predicates tend to take what we have analysed as finite complements (which Grano 2012 analyses in a different way).

${ }^{21}$ Potential complications arise from the fact that not all of the finiteness diagnostics hold in all cases. For example, in the case of sentential subjects, object shift is not possible and the aspectual marker $l e$ is only marginally possible:
} 
In summary, if nominative Case licensing is dependent on (some aspect of) finiteness, the ungrammaticality of overt subject DPs in (independently diagnosable) non-finite clauses is evidence for the relevance of Vergnaud licensing in these languages.

\section{2. (Hyper)Activity}

Hyperactive agreement (Carstens 2011) is not easy to diagnose in languages lacking verbal inflection. However, given that the languages under discussion all have clear finiteness diagnostics, it is nonetheless possible to ask whether hyperraising is possible.

Yoruba and JC do not permit hyperraising but do have copy raising:

a. Komiin laik se di piknia go ron we. seem like COMP the child PROG PROSP run away 'It seems like the child is going to run away.'

(Durrleman-Tame 2007:108)

b. Di pikni komiin laik se *(im) a go ron we. the child seem like COMP 3SG PROG PROSP run away 'The child seems like he is going to run away.'

(54) a. Dọ̀tun jọ [pé ó nífẹe Sídí].

Dotun resemble that $3 \mathrm{SG}$ love Sidi

[Yoruba] 'Dotun seems like he loves Sidi.'

b. Ó jọ [pé Dọ̀tun nífèe Sídí].

it resemble that Dotun love Sidi

'It seems that Dotun loves Sidi.'

Copy raising is observed in a diverse range of languages with and without morphological case (e.g. English, Swedish, Greek, Samoan, Hebrew, Irish, Haitain Creole, Igbo, Persian and Turkish - see Adesola 2005, Asudeh \& Toivonen 2006, 2012 and the references cited therein). Although this phenomenon poses potential challenges for Case Theory, it is very generally analysed as a phenomenon distinct from hyperactivity: Potsdam and Runner (2001) propose that in the English construction 'John seems like he's ill', the matrix subject is a thematic argument of seem, base generated in the matrix clause and so no raising takes place. Note that in English, copy raising structures nonetheless alternate

\begin{tabular}{llll}
\hline (i) & *[Zhangsan & wancan zhunbei] shi qiguaide \\
& Zhangsan & dinner make & is strange \\
(ii) & $*[$ wancan & zhunbei] shi & qiguaide \\
& dinner & make is & strange \\
(iii) & ??Zhangsan qu Taibei le shi & qiguaide \\
& Zhangsan go Taipei ASP is & strange
\end{tabular}

We leave a full investigation of these issues to one side here, taking the modals to be the more robust diagnostic for finiteness in Mandarin. It is possible that there are independent semantic/pragmatic reasons, then, why (i)-(ii) are ruled out. Note also that Hu et al. (2001) point out that the future marker yao can surface in control complements. We attribute this to a different between the two future markers akin to the difference between modals and aspectual auxiliaries in English. 
with an expletive, as Asudeh \& Toivonen (2006: 3) note, making them look very similar to the Yoruba examples above:

(55) a. Thora seems like she adores popsicles.

b. It seems like Thora adores popsicles.

Superficially, Mandarin and Thai appear to show hyperactivity:

(56) a. Mǔan wăa Cơn cà?/ khuuj rák Saarăa.

[Thai] look.like COMP John IRR/PERF love Sara

'It looks like John will/used to love Sara.'

b. Cojn mǔan wăa cà?/ khuuj rák Saarăa.

John look.like COMP IRR/PERF love Sara

'John looks like (that he) will/used to love Sara.'

(57) a. Keneng Zhangsanhui zhunbeiwancan. be-likely-to Zhangsanwill prepare dinner

[Mandarin]

'It is likely that that Zhangsan will prepare the dinner.' (Lin 2011: 68)

b. Tanbai-shuo, Zhangsan keneng zhunbei wancan.

frankly-speaking Zhangsan be-likely-to prepare dinner

'Frankly speaking, Zhangsan may prepare the dinner.' (Lin 2011: 63)

Upon closer inspection, however, neither of these examples patterns with hyperraising. Keneng in the Mandarin examples is probably a sentential adverbial (Pan \& Paul 2014) rather than a raising verb. The interpretation of the Thai examples reveals them to be an example of copy raising (in a null subject language). As Asudeh \& Toivonen (2006), note, copy raising, unlike (hyper)raising, fails what they call the puzzle of the absent cook. Consider a context where "A and B walk into Tom's kitchen. There's no sign of Tom, but there are various things bubbling away on the stove and there are several ingredients on the counter, apparently waiting to be used." In such a contexts, they note, it would be odd to use the copy-raising example in (58a), whereas the raising example in (58b) is wholly natural:

(58) a. \#Tom seems like he's cooking.

b. Tom seems to be cooking.

In Thai, the preferred contexts for the raised and non-raised subjects differ in such a way that a copy-raising analysis is most likely.

(59) a. Naruadol mǔan wâa kamlan plùuk bâan.

Naruadol look.like COMP PROGR build house

'Naruadol seems like he is building a house.'

context: you see Naruadol doing something

b. Mǔan Naruadol wâa kamlan plùuk bâan.

look.like Naruadol COMP PROGR build house

'It seems like Naruadol is building a house.'

context: you pass by his house and see a load of building materials 
The apparent optionality in (56)-(57) would thus be wholly parallel with that observed in Jamaican Creole and Yoruba, with the additional complication that both the expletive and embedded subject are null in Thai.

In conclusion, while three of the four analytic languages display copy raising, none of them has hyperraising. For this reason we can tentatively conclude that in all four languages the Activity condition holds, which in turn is evidence that DPs are subject to Vergnaud licensing in these languages.

\subsection{GF-based asymmetries}

The fourth diagnostic concerns asymmetries between arguments which require reference to grammatical functions. This diagnostic holds only unidirectionally: a language in which such asymmetries exist must have Vergnaud licensing, but in the absence of such asymmetries we cannot conclude anything about the relevance of Vergnaud licensing in a given language.

The first such asymmetry, observed in Jamaican Creole, is 'that-trace effects', which Pesetsky \& Torrego (2001) attribute to asymmetries in Caselicensing, specifically to the fact that nominative case is a [uT] feature so that subject movement to spec CP interacts with the C-T relation. Even in approaches such as that of Erlewine $(2014,2016)$ which attribute the effect to anti-locality, it is the licensing of the subject which is responsible for subject movement to spec TP:

(60) a. John tink dat Mari taak tu Sara.

'John thinks that Mari talks to Sara.'

b. A huu John tink dat Mari taak tu?

FOC who John think COMP Mary talk to

'Who does John think Mary talked to?

c. A huu John tink (*dat) ben taak tu Sara?

FOC who John think COMP PERF talk to Sara

'Who does John think talked to Sara?'

(cf. Durrleman-Tame 2008: 98)

Yoruba displays a similar subject/non-subject asymmetry. Unlike non-subject extraction, subject extraction in wh-questions or focus constructions requires the presence of a non-agreeing expletive pronoun (Adesola 2005, citing Pulleybank 1986, Carstens 1986):

(61) a.

$$
\begin{aligned}
& \text { a. Kíi ni Àdìo rà (*á) })_{i} \text { ? } \\
& \text { what be Adio buy it } \\
& \text { 'What did Adio buy?' } \\
& \text { b. Ta ni *(ó) ra işu? } \\
& \text { who be it buy yam } \\
& \text { 'Who bought yams?' }
\end{aligned}
$$

[Yoruba]

(Adesola 2005: 88)

(Adesola 2005: 91)

We assume that expletive insertion of this kind avoids the that-trace effect as the argument can be extracted from its low post-verbal position (Rizzi 1982). JC and Yoruba thus test positive on this diagnostic. 
Yoruba furthermore shows a superficially very different grammatical process, which has also been argued to be sensitive to accusative Case: low tone deletion (LTD). LTD has been argued to take place only where the verb is followed by an overt accusative Case-marked XP (Carstens 1987, Déchaine 2001, Ajíbóyè et al. 2011). Thus, DP complements of V trigger low tone deletion (62), but PP complements (63) and adjuncts (64) do not and nor do clausal complements:

(62) /gbà așo/ > [gba așo] 'take cloth' /gbà ìwé/ > [gba ìwé] 'take book' (Carstens 1987: 3)

[Yoruba]

(63) Opé wà/*wa nílé Fúnké

Ope is $\mathrm{CM}+$ house Funke

'Ope is at Funke's house.' (Carstens 1987: 8)

(64) mo sùn/*sun [bí ọmọ kékeré]

I slept like child small

'I slept like a baby.' (Carstens 1987: 7)

As Déchaine (2001: 89) shows, there are even minimal pairs where the same DP triggers LTD where it functions as a complement but not where it is an adjunct:

a. Mo ta jábu-jàbu.

sell unimaginable

[Yoruba]

'I sold unimaginable things.' (i.e. everything you can think of)

b. Mo tà jábu-jàbu.

I sell unimaginable

'I sold (my wares) incredibly.' (i.e. very successfully)

(Déchaine 2001: 89)

In gerunds, postverbal (genitive) subjects fail to trigger LTD unlike complements (Déchaine 2001: 89), presumably because only the latter have accusative Case.

Finally, bisyllabic verbs assign genitive Case (or more neutrally, select for inherent Case-marked genitive complements) and also fail to trigger LTD:

(66) Mo féèlì rè̀.

[Yoruba]

I failed 3SG.GEN

'I failed it.'

(67) Mo féèlì/*féèli ìdánwò.

I failed exam (Carstens 1987: 10)

'I failed the exam.'

LTD can therefore be taken as further evidence for the role of Vergnaud licensing in Yoruba.

We have found no evidence for any GF-related asymmetry in Mandarin, Thai, Luganda or Makhuwa. This could be either because no such asymmetry exists or because we have simply failed to find it in these languages. Either way, 
the result would be consistent with these languages nonetheless having Vergnaud licensing and a concomitant notion of grammatical function. The status of that-trace effects remains undecided but even if it is a universal effect arising from something as deep as criterial freezing (Rizzi 1997, 2015), then even well studied languages have well studied ways to circumvent this effect (see footnote 8 above). The lack of such an asymmetry can therefore not be taken as evidence against the relevance of Vergnaud licensing in a given language.

\subsection{Passive agent}

The obligatory licensing of an overt agent DP in a passive can only be tested if the language in question actually has a passive. This unfortunately makes this diagnostic inapplicable in three of our four analytic languages. Nonetheless, in Jamaican Creole, which does have a true passive, this diagnostic provides indirect evidence that DPs must be Vergnaud licensed.

Yoruba lacks a passive, and the constructions that are often labelled passives in Thai and Mandarin have properties more reminiscent of toughconstructions (see Sudmuk 2003 for Thai and Huang 1999 for Mandarin, but see also Biggs 2014 for a critique of this analysis and an alternative view). ${ }^{22}$ Thus the status of the "passive" morphemes bei in Mandarin (68) and thùuk in Thai (69) is debatable. Furthermore, Thai thùuk is only used with adversatives (Filbeck 1973, among others); in other contexts a topicalisation construction (70) is used, making any test involving a passive inapplicable.

Zhe ben shu bei haizi-men du le. DEM CL book BEI children read PERF.

[Mandarin]

'The books were read by the children.'

Năysǔuu lêm nán thùuk dèk làw nán thamlaaj láæw. book CL DEM.DIST THUUK child group DEM.DIST destroy PERF 'The book was already destroyed by the children.'
Năysǔu lêm nán | dèk làw nán Tàan lǽæw. book CL DEM.DIST child group DEM.DIST read PERF 'That book, the children read (it).' / 'The book was read by the children.'

Jamaican Creole has a 'short passive' (LaCharité \& Wellington 1999, Winford 1993), but it does not allow for overt agent phrases. ${ }^{23}$ One possible analysis of this fact is that overt referential agents cannot be overtly expressed because they cannot be licensed. ${ }^{24}$ If so, then the ban on overt agents in JC passives can be taken as further evidence for the relevance of Vergnaud licensing in this language.

\footnotetext{
${ }^{22}$ Victor Manfredi notes that Yoruba does, however, have what looks like a medio-passive or middle. Given that such constructions usually disallow the overt expression of the suppressed agent, our test is nonetheless inapplicable in Yoruba.

${ }^{23}$ A potential preposition would be wid 'with', which Veenstra (1990) however shows to form an instrumental (not agentive) phrase.

${ }^{24} \mathrm{We}$ thank an anonymous reviewer for pointing out this possibility.
} 
a. Di bred it af (*bai im)

[JC]

The bread eat up by him

'The bread was eaten.'

b. Di leta rait (*bai im)

the latter write by him

'The letter was written.' ～(LaCharité and Wellington 1999: 260)

Note that it is not the case that JC lacks the relevant kind of preposition, as it actually allows a by phrase with anti causatives:

Di windo opn bai iself.

the window open by itself

'The window opened by itself.' ～（LaCharité and Wellington 1999: 271)

Where the agent is overtly expressed in Jamaican Creole, a focus construction seems to be used, rather than the passive:
A di buk di pikni dem ben riid.
FOC DET book DET pikni PL PAST read.
'It was the book that the children read.'

Although this last diagnostic is not applicable to most of the analytic languages in our sample, then, the data for Jamiacan Creole are suggestive. Morever, the other three diagnostics provide evidence in favour of nominal licensing in all four analytic languages. There seems to be no analytic language which patterns with Luganda in not requiring DPs to be Vergnaud licensed. While further detailed investigation of other analytic languages is clearly necessary, we nonetheless take this to indicate that Vergnaud licensing is a pervasive feature of natural language, even in languages that lack case and agreement morphology.

\section{Less reliable diagnostics}

Thus far, we have discussed five diagnostics and applied them, where possible, to the six languages under discussion. There are, however, four further diagnostics introduced in section 2 which we have not yet considered beyond their application to English. This is because we find these diagnostics to be less reliable when applied to the languages in our sample. We now discuss these diagnostics in turn, illustrating the problems with data from the six languages we examined, which pattern as in Table 3. One diagnostic is theoretically suspect, one yields contradictory results and the remaining two are difficult to apply in the languages in question for reasons to be discussed below.

\begin{tabular}{|l|l|l|l|l|l|l|}
\hline & Mandarin & Thai & Yoruba & JC & Makhuwa & Luganda \\
\hline 6. Morphology & 0 & 0 & + & 0 & 0 & 0 \\
\hline 7. Anaphors & - & - & + & + & n.a. & n.a. \\
\hline 8. Assigners (A/N vs. V/P) & + & + & $+?$ & $+?$ & + & 0 \\
\hline 9. Assignees (CP vs. DP) & n.a. & n.a. & $+?$ & $+?$ & $?$ & $?$ \\
\hline
\end{tabular}


Table 3: Case diagnostics (+ evidence of Vergnaud licensing, - evidence for lack of Vergnaud licensing , 0 compatible with either, n.a. test cannot be applied, ? no data or unclear)

\subsection{Morphological case}

On a traditional view of morphological and abstract Case, the fact that a language has morphological case distinctions which track not theta-roles but grammatical functions tells us that said language has Vergnaud licensing (assuming with Legate 2008 that morphology needs something to spell out).

None of the six languages under investigation mark morphological case on DPs. However, Yoruba has evidence of morphological case in its pronominal system, making a distinction between nominative, accusative and genitive in its weak (clitic) pronouns: ${ }^{25}$

(74) Yoruba pronominal paradigm - weak pronouns (Bamgboṣe 1966:105106)

$\begin{array}{llll}\text { subject } & & \text { object } & \\ \text { singular } & \text { plural } & \text { singular } & \text { plural } \\ \text { 1. mo } & \text { a } & 1 . \mathrm{mi} & \text { wa } \\ 2.0 & \text { e } & 2 . \text { o e }_{1} & \text { yín } \\ \text { 3. ó } & \text { wọ́n } & 3 . V-\text { redup. }^{26} & \text { wọn }\end{array}$

Given traditional assumptions, this would entail that Yoruba tests positive for Vergnaud licensing on this diagnostic. ${ }^{27}$

However, as an anonymous reviewer points out, some theories of morphological case explicitly claim that morphological case is not parasitic on nominal licensing (see Marantz 1991, Pesetsky 2014). If such approaches are correct, even for some languages, then it follows that the presence of morphological case cannot be taken as (indirect) evidence of Vergnaud licensing. Even if such approaches are shown to be misguided (which seems unlikely), the point stands that many languages show mismatches between morphological case and grammatical function, so morphology can be taken at best as a very unreliable indicator of abstract licensing. We discussed examples from Icelandic and morphologically but not syntactically ergative languages in section 2 , but the same point can be made with reference to differential case marking (e.g. Aissen

\footnotetext{
${ }^{25}$ The same is not true of its strong pronouns which are invariant for case (Ogunbowale 1970: 65). ${ }^{26}$ Ogunbowale (1970: 70) notes that 3SG objects can be realized via (a) the strong invariant 3SG pronoun òun, (b) reduplication of the vowel of the verb/preposition (as in i), or (c) the genitive pronoun rè after polysyllabic verbs.

(i) a. gbé e 'carry it'

b. wò ó 'look.at her'

c. jẹ ế 'eat it'

27 The same could be said about Bantu subject and object markers that differ in morphological form. However, it is debatable whether these markers on the verb are incoporated pronouns or agreement. Assuming with Roberts (2010) that clitics are the spell-out of an Agree relation on a functional head, we take subject and object markers in Luganda and Makhuwa to be the morphological realisation of $\phi$ agreement on $\mathrm{v}$ and $\mathrm{T}$ heads (cf. Iorio 2014 and Van der Wal $2015 \mathrm{~b}$ ), and not an instance of morphological case.
} 
2003, Jelinek \& Carnie 2003, De Hoop and de Swart 2008, Dalrymple and Nikolaeva 2011 amongst many others) and co-dependent/inverse marking (Béjar and Rezac 2009, Keine 2010, Bárány 2015).

Moreover, the reverse also holds: the lack of morphological case cannot be taken as evidence for the lack of Vergnaud licensing either. Even according to Chomsky's $(2000,2001)$ formulation in Case Theoretic terms, it is made very explicit that syntactic dependencies need not always be realised morphologically. This means that whether a language has or lacks morphological case actually is uninformative as to whether it has Vergnaud licensing.

\subsection{Anaphors}

The ban on subject anaphors in (at least) English, Italian and Icelandic can directly (via morphology) or indirectly (via agreement) be attributed to Vergnaud licensing. Although early accounts of this effect attributed it to the accidental inexistence of nominative anaphors (Brame 1977, Koster 1978, Anderson 1982, Maling 1984, Everaert 1991), the current dominant analysis in the generative literature attributes it to the Anaphor Agreement Effect (AAE), a general ban on agreeing with anaphors (Rizzi 1990, Woolford 1999). ${ }^{28}$

The connection to Vergnaud licensing relies on the assumption that (i) agreement is indicative of Agree and (ii) Agree is dependent on activity, being brought about by the presence of an unvalued [uCase] feature, on a not-yetlicensed nominal (but see but see Baker 2015, Preminger 2014, Bárány 2015 for the severing of Case and Agree). Given these assumptions, the availability of subject anaphors functions as a bidirectional diagnostic: if a language has subject anaphors it cannot have subject agreement and by implication cannot have abstract Case (or else the subject would be left unlicensed). Conversely, if a language displays a ban on subject anaphors, it follows that the language in question Agrees with the subject and hence must have Case.

This analysis turns out to be problematic in different ways. We first present the data from the Asian languages. Mandarin is well known to permit subject anaphors (Fisher 1988, Huang 1982):29

Zhangsan $_{i}$ shuo ziji $i_{i}$ hui lai.
Zhangsan say self will come
Lit. 'Zhangsan said self $_{i}$ will come.'

[Mandarin]

(Huang 1982:331)

Under the approach just sketched, these data can be interpreted in one of three ways: (a) the AAE is correct, Mandarin lacks Vergnaud licensing and our previous diagnostics are unreliable; (b) the AAE is simply incorrect; or (c) the AAE has

\footnotetext{
${ }^{28}$ The older analysis first proposed by Brame (1977) is also problematic. JC and Yoruba both display the ban, but in neither case is it plausible to attribute this to a ban on nominative anaphors. JC makes no morphological case distinctions and Yoruba anaphors take a nominal form (literally 'his body') which again would not be expected to inflect for case in that language. We thank an anonymous reviewer for changing our mind on this point.

${ }^{29}$ It is also noteworthy that, at least in Mandarin, these anaphors do not require a linguistic antecedent and can be contextually bound:

(i) Ziji zuo ye xing.

self do also okay

'It can be done by ourselves.'
} 
nothing to do with Vergnaud licensing but concerns morphological marking only. Option (c) is taken in current approaches to the AAE:

(Tucker 2011: 30, via Sundaresan 2015)

(76) Anaphors do not occur in syntactic positions construed with covarying $\phi$ morphology.

As Woolford (1999) shows, the AAE holds not just of subjects but also of objects, with languages displaying a variety of ways to avoid the AAE (see also the overview in Sundaresan 2015). This would account, then, for the fact that objects can be anaphors if there is no morphological marking of object agreement, as indeed there isn't in Jamaican Creole or Yoruba. However, under this morphological definition the AAE restriction on subject anaphors in Jamaican Creole and Yoruba cannot be accounted for: $:^{30,31,32}$
a. Tóbi $i_{i}$ i
Fìjàbíj han $\quad$ ara rè̀ $]_{i / j}$.
Tobi PART Fijabi show body his
'Tobi showed Fijabi to himself/herself.'
b. Tóbi $i_{i}$ sọ [ìtàn [ara rè̀ $\left.]_{i}\right]$ fún Fìjàbí.
Tobi tell story body his for Fijabi
'Tobi told the story of himself to Fijabi.'
c. *Tobi rò pé [ara rẹ̀] tọ̀nà.
Tobi think that body his right
'Tobi thinks that himself is right.'

[Yoruba]
d. Tóbi $i_{i}$ rò pé [ìtàn nípa [ara rẹ̀ $\left.]_{i}\right]$ sàjèjì
Tobi thinks that story about body his strange
'Tobi thinks that stories about himself are strange.'

(78) a. $\quad$ ?* Harri tink se imself nais. [JC] $^{*}$

'Harry thinks that himself is nice.'

b. Harri tink se im nais.

'Harry thinks $_{\mathrm{i}} \mathrm{i}_{\mathrm{j} j}$ is nice.'

c. Harri tink se picho a imself nais.

'Harry thinks that pictures of himself are nice.'

\footnotetext{
30 'Show' in Yoruba appears to be a particle verb fihàn which appears discontinuously in ditransitive uses. We take hàn to be verbal and $f i$ to be a particle as hàn is subject to low tone deletion, a property of verbs.

${ }^{31}$ Victor Manfredi reminds us to mention that Yoruba would use a strong pronoun or so-called logophor here (see Adesola 2005 for extentive discussion).

${ }^{32}$ Note that the 'body' anaphor in Yoruba is a true anaphor (unlike some East-Asian body part anaphors which escape the AAE), requiring local binding (Reuland \& Schadler 2011, cf. Schladt 2000, Heine 2000).
} 
If the AAE is about overt agreement then the Yoruba and JC pattern cannot be subsumed under this analysis, because these languages lack overt agreement and yet display the AAE. Considering that we have positive evidence for the presence of Vegnaud licensing from other tests, and considering that the relation between Vergnaud licensing and Agree/agreement is debated, we maintain that more research into the $\mathrm{AAE}$ is required before conclusions can be drawn but that the lack of subject anaphors should not be used as a diagnostic for Vergnaud licensing.

For the sake of completeness we show how this diagnostic is nonapplicable in Thai, Luganda and Makhuwa. The AAE and its predictions would seem easiest to test in languages that do actually show agreement, but unfortunately, our two Bantu languages being pro-drop, (anaphoric) pronouns are not necessary (79a). When anaphors do occur, they are better analysed as intensifiers: in (79b) kyennyini, which could be thought of as an anaphoric pronoun, cannot appear without the strong pronoun $y e$.

$$
\begin{aligned}
& \text { A-lowooza nti mutuufu. } \\
& \text { 1SM-think COMP 1.right.one } \\
& \text { ' } \mathrm{He}_{\mathrm{i}} \text { thinks that he } \mathrm{e}_{\mathrm{i} / \mathrm{j}} \text { is right.' }
\end{aligned}
$$
b. Hari a-lowooza nti *(ye) kyennyini y-a-gula
1.Harry 1SM-think COMP 1.PRO self 1SM-PAST-buy emmotoka ennuungi.
9.car 9.good
'Harry thinks that he himself bought a good car.'

The canonical reflexive in both languages is a morphological marker on the verb:
(80) Menínú o-ná-mwíi-shóvá wa-tsulú wa ethaápwa. [Makhuwa] 1.boy 1SM-PRES.DJ-REFL-push 16-above 16-CONN 9.wood
'The boy pushes himself on top of the wood.'

The diagnostic is equally non-applicable in Thai, but for a different reason. Thai seems to allow an anaphor in subject position (81), but upon closer inspection, this turns out to be a 'protected anaphor', i.e. the 'body' NP does not need to be locally bound, as shown by the long-distance binding in (82).

(81) Hæærîi khít wâa [tua Peey] thùuk. Harry think COMP body REFL be.right Lit. ' Harry ${ }_{i}$ thinks that self $f_{i}$ is right.'
hæærîi khít wâa Saarăa rák tua ?eey Harry think comp Sara love body REFL 'Harry thinks that Sara likes him(self).'

For multiple reasons then, this test fails as a diagnostic of Vergnaud licensing. 


\subsection{Assigners}

In GB Theory, it was observed that in many languages some categories (verbs and adpositions) appear to be Case-licensers whereas others do not (adjectives and nouns). There are various methodological issues that make this diagnostic difficult to apply to the languages in our sample, and render it a rather dubious diagnostic for Vergnaud licensing.

A first point concerns the universality of categories: not all of the languages clearly display the four-way category distinction (Verb-AdjectiveNoun-Adposition) familiar from Indo-European languages. We will not digress into the more fundamental issue of the cross-linguistic validity of syntactic categories (see Haspelmath 2010) but will assume, for sake of argument, that there are core categories with similar syntactic behaviour across languages (see Baker 2003). One problem here is that there is a substantial risk of circularity in the establishment of the category of adjectives: the inability to license complements is often taken as the core diagnostic distinguishing adjectives/adverbs from verbs (in the absence of adverbs which modify only adjectives/adverbs and not verbs, such as very). We therefore need independent tests for the V/Adj distinction if this diagnostic is to be used as evidence for the presence of abstract Case, to avoid circularity.

A second point concerns the argument structure of nouns: what is the status of adpositions/linkers in noun phrases? Do nouns have arguments that need to be licensed by a linker or adposition (as in 'fear of ghosts') or is the linker actually required to introduce the argument in question? The argument structure of nominals is a theoretical issue that goes well beyond the aims of the current paper (see Grimshaw 1990, Kayne 2010 amongst many others). More generally, the fact that linkers occur in contexts where it is not generally assumed that Case is required (e.g. adjectival/adverbial modification in some languages) suggests that the former might perform some other function than nominal licensing, as has been claimed for the Persian ezafe construction (Ghomeshi 1997, Karimi 2007).

These issues make it difficult to draw clear conclusions from this diagnostic. We can clearly see that none of the languages under investigation needs a linker with the complements of verbs or prepositions. The question is, then, whether nominal arguments of nouns and adjectives require a linker; if the presence of a linker with arguments of nouns and adjectives is taken to have licensing as its only function, then all of the languages under discussion show the effects of Vergnaud licensing, even Luganda. This, in addition to the point that linkers and adpositions are distinct grammatical entities (see Philip 2013), suggests the unreliability of this diagnostic. We discuss the data for each of the languages to illustrate the problematic aspects of this diagnostic. 


\subsubsection{Mandarin}

The most straightforward case study is Mandarin, where nominalisations (which unlike verbs are phrase-final) can only take nominal arguments if they are introduced by a preposition (Huang, Li \& Li 2009: 11-12): ${ }^{33,34}$
a. meiti boadao-le
na-ci shigu
media report-ASP that-CL accident
'the media reported that accident.'
b. meiti*(dui) na-ci shigu de boadao media on that-CL accident DE report
'the media's report of that accident.'

[Mandarin]

Despite certain similarities between verbs and adjectives, Huang, Li \& Li (2009:22), building on much previous research, argue convincingly that the two categories can be distinguished, and that where Adj takes a complement, the latter must also be introduced by the preposition dui 'on':

Wo dui tade qushi feichang shangxin [Mandarin]

I on his pass.away extremely sad

'I am extremely sad about his passing away.'

b. *wo feichang shangxin tade qushi

I extremely sad his pass.away

[Mandarin, Huang, Li \& Li 2009: 22]

In this way, adjectives/nouns contrast with verbs and adpositions in requiring nominal arguments to be introduced by a preposition, suggesting that DPs need to be Vergnaud licensed in this language. ${ }^{35}$

\subsubsection{Jamaican Creole, Yoruba and Thai}

In spite of various methodological challenges, the evidence from JC, Yoruba and Thai, does suggest that DP arguments of N/A vs. V/P consistently behave differently.

In Jamaican Creole, nominal arguments of adjectives must be introduced by a preposition (85), whereas nouns (86), prepositions (87) and verbs can take DP arguments without a linker/preposition.

\footnotetext{
${ }^{33}$ As Huang, Li \& Li (2009: 12) note, a preposition is required only where the nominal also contains an overt subject. This is possibly because in the absence of an overly expressed subject the object can be licensed via the Case normally available for the subject (cf. English passive nominalisations).

${ }^{34} \mathrm{Li}$ 's $(1990,2008)$ interpretation of these facts is slightly different as she takes de to be a caseassigner. This raises some questions, though, as de, like ezafe and linkers more generally, also introduces elements which are not expected to require Case (e.g. clauses, adjectives - see also the discussion of Luganda below). In other respects clauses, for example, pattern differently from nominals, suggesting they do not (always) receive Case (Li 2005, 2007, 2008).

${ }^{35}$ Much of the literature on Mandarin has focused on the contrast in the distribution of prepositional phrases vs. nominals (where 'post-positional phrases' pattern with nominals) (see Koopman 1984, Travis 1984, Li 1990, 2008, Biggs 2014). While nominals are argued to occupy Case positions, true PPs are argued to be Case resistant (Stowell 1981). Space prevents us from discussing these facts here. Note however, that it is not easy to convey the notion of Case resistance using Minimalist tools such as Agree.
} 
a. $\quad$ afried $*(a)$ di enimi

b. wori *(bout) di fuucha

'worried about the future'

(86) a. di enemi haraival

'the enemy's arrival'

b. Li faada

'Li's father'

(87) a. bifuor dinna

'before dinner'

b. antel summa

'until summer'

On the face of it, this contrast suggests that adjectives unlike other categories fail to be Vergnaud licensors. This is surprising in the contexts of the English contrasts, presented above as DP arguments of nouns do not need to be introduced by a linker, it seems, suggesting that nouns are themselves licensors. It is possible, however, that nouns in JC assign a structural Case, possibly a construct state or juxtaposition genitive, obviating the need for an adposition/linker. We leave a full investigation of this possibility to future research.

In Yoruba, we must distinguish between two types of nominals: possessors of kinship terms are introduced via a linker (88), whereas derived nominals (gerunds) can take a genitive argument (89), depending on the height of the nominalisation (Déchaine 2001).

(88) Bàbá a Báyọ̀

Father LNK Bayo

[Yoruba]

'Bayo's father' or 'Bayo who is a father (to me)'

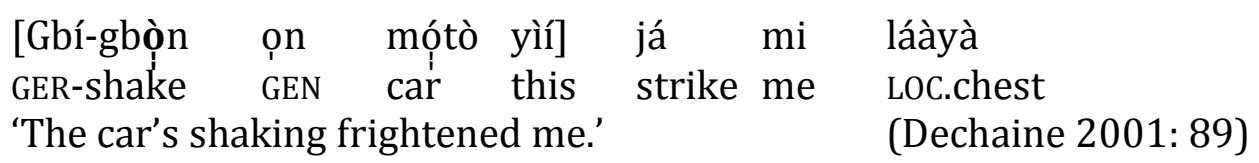

In the case of kinship terms, the ambiguity of interpretation suggests that the linker is simply a marker of adjunction, and so is probably unrelated to Vergnaud licensing. ${ }^{36}$ The nominalisation facts are more obviously related to Vergnaud licensing. When the target of nominalisation is the root $V$, as in (89), the subject surfaces with genitive case and the verbal root fails to undergo low tone deletion, which is a defining characteristic of verbs which licenses accusative case in the language (see section 4.3), thus resulting in a fully nominal gerund. This gerund accordingly requires the genitive marker to introduce overt arguments. When nominalisation targets a higher verbal projection, above little $\mathrm{v}$, the gerund

\footnotetext{
${ }^{36}$ Our thanks to Victor Manfredi for pointing this out to us.
} 
assigns accusative case (as in English; see Abney 1987), and the verb does undergo low tone deletion, as in (90).

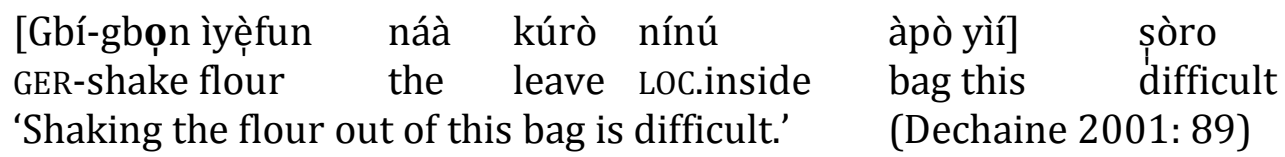

In terms of the other categories, one challenge is that Yoruba has very few clear adjectives (Madugu 1976). The only clear cases are the items rere 'good' and ńlá 'large' which can only occur as attributive modifiers of nouns and cannot be used comparatively. Many adjectival concepts are actually rendered as stative verbs in Yoruba, which would entail that this diagnostic is not applicable in the language. There is, however, evidence for an adjective/noun vs. verb distinction if we consider the behaviour of gerunds (nominalised verbs) (Rowlands 1969: 121), which can then be used as attributive adjectives (Rowlands 1969, Madugu 1976). Crucial to the discussion at hand is the fact that these nominalised adjectives can only take nominal arguments introduced by an adposition, unlike verbs and adpositions, which can take bare DP arguments, again suggesting an asymmetry related to Vergnaud licensing.

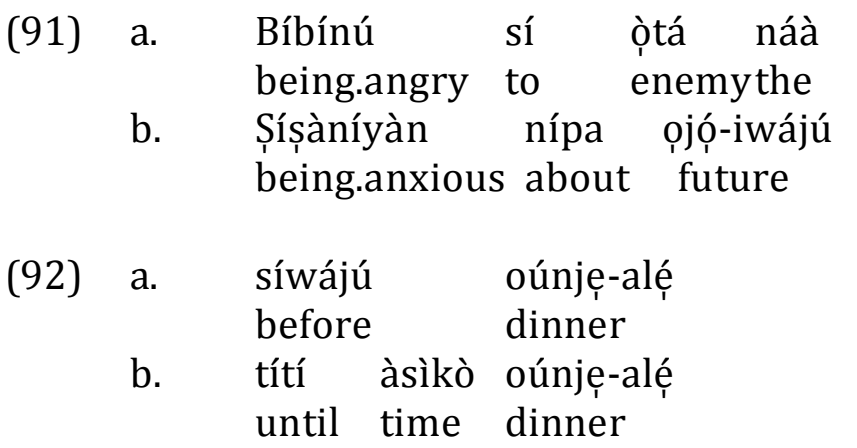

[Yoruba]

In Thai, this diagnostic raises similar difficulties. We mention three. First, Thai 'adjectives' are flexible between being adjectival and verbal, ${ }^{37}$ and can be characterised as adjectival predicates (Prasithrathsint 2000). Taking klua 'afraid' as an example, it behaves as an adjective in being awkward with the verbal auxiliary dâj 'can' (93) and allowing a superlative (94), but it functions as a verb in allowing aspectual auxiliaries (95) and not needing a copula in predication (96).

?? klua sàttruu dâj
fear enemy POT
'can fear the enemy'

[Thai]
(94) klua thîi-sùt
afraid the.most
'most afraid'

\footnotetext{
${ }^{37}$ See Bhat \& Pustet (2000) for other South-East Asian languages that do not have a distinction between adjectives and verbs.
} 
(95) klua sàttruu paj lǽæw

be.afraid enemy CONT PERF

'already fearing the enemy'

(96) Khon níi *(pen) klua.

person this COP afraid

int. 'This person is afraid.'

Consequently, the fact that an adjectival in Thai does not require (and cannot take) a marker, as in (97), does not reveal anything about the licensing by A vs. V assigners.

(97) klua sàttruu

[Thai]

be.afraid enemy

'to fear the enemy' / 'to be afraid of the enemy'

The words that do show primarily adjectival properties, as diagnosed by a number of other properties in Post (2008), are adjectives that do not take complements, such as 'heavy', 'clever', or 'beautiful'.

A second problematic aspect of this diagnostic in Thai is the fact that the possessive marker is optional for kinship terms, as in (98).

(98) phôว (khว̌วy) lii

father POSS Li

[Thai]

'Li's father'

However, this optionality only surfaces for pronominal possessors and kinship terms (Huang and Jenks 2013), and disappears when an adjective intervenes (Peter Jenks, p.c.), suggesting again that a null construct case of juxtaposition genitive is at stake. Once we control for this possibility, the obligatory presence of the linker in examples like the following is arguably evidence of Vergnaud licensing:

$$
\begin{aligned}
& \text { maa antalay *(khong) Nit } \\
& \text { dog dangerous Poss Nit } \\
& \text { 'Nit's dangerous dog' }
\end{aligned}
$$

Third, two types of nominalisation are available. Thai, like Yoruba, also has high and low nominalisation strategies (Jenks 2011, 2014). The high nominalisation is illustrated in (100) and (101). This can be thought of as a type of noun incorporation, or a high nominalisation where the verb retains the ability to assign accusative Case. ${ }^{38}$

(100) khwaam-klua-maa

${ }^{38}$ The fact that a modified sentence in (i) is judged as "sounding a lot better without the demonstrative" suggests an incorporation analysis.

(i) ? khwaam-klua măa tua níi (khoy chăn)

QUAL.NOMZ-fear dog CL.ANIM DEM POSS 1SG

'my fear of this dog' 
QUAL.NOMZ-fear-dog

'fear of dogs' (Peter Jenks p.c.)

(101) kaan-khǐian còt-măay nâabùa

NOMZ-write letters boring

'writing letters is boring' (Jenks 2014: 315)

Crucially, adding the possessive marker in (100) results in a reading of the modifier as a possessor, that is, in (102) it can no longer mean 'fear of dogs' but must be 'the dog's fear (of sth else)'.

(102) khwaam-klua (phǐi) khว̌j’ maa QUAL.NOMZ-fear ghost POSS dog '(the/a) dog's fear (of ghosts)' (Peter Jenks, p.c.)

This suggests that the possessive marker is present only if the nominalisation targets a low node, i.e. when the verb cannot itself license the complement. If the presence of the marker depends on high vs. low nominalisation, we predict that the possessive correlates with other properties of high vs low nominalisation. The presence of an agent/causer is one such property. In low nominalisations the internal argument is licensed by the possessive marker, leaving no room for other arguments, whereas in high nominalisations the verb licenses the internal argument, which leaves room for an agent/causer to be licensed by the possessive marker. ${ }^{39}$ In low nominalisations we thus find the obligatory presence of the possessive marker, the ungrammaticality of adding an overt agent/causer as in (103a), and the infelicitous continuation in (103b) implying an agent/causer:

(103) a. *kaan tæ̀æk khว̌эy kæ̂æw dooj dèk chaaj (sà?nùk dii) [Thai] NOMZ break POSS glass by child male be.fun well 'the breaking of a glass by the boy (is fun)' / 'the glass's breaking by the boy (is fun)'

b. kaan tæ̀æk khว̌j引 kæ̂æw (?? sanuk dii) NOMZ break POSS glass fun well 'the breaking of a glass (is fun)' / 'the glass's breaking (is fun)'

In contrast, the high nominalisation (a V-N compound) counterpart in (104) allows for the presence of an agent/causer (marginally, but much better than the low nominalisation), and can felicitously be continued by a predicate indicating the presence of an external argument.

(104) a. ? kaan tham kæ̂æw tæ̀æk dooj dèk chaaj (sà?nùk dii) [Thai] NOMZ make glass break by child male be.fun well 'breaking glass by the boy (is fun)'

b. kaan tæ̀æk kâæw (sanukdii) NOMZ break glass fun well 'breaking glass (is fun)'

\footnotetext{
${ }^{39}$ See Huang and Jenks (2013) for an analysis of khว̌วy as a predicate forming operator.
} 
In summary, we encounter a potential effect of licensers in JC, Yoruba and Thai, particularly when we pay attention not only to common nouns, but also to nominalisations. In all cases, there are many further questions which require investigation, though, and the theoretical issues regarding the categorial status of nouns, verbs, prepositions and adjectives, as well as the debate around the argument structure of nouns and the licensing vs. introducing functions of linkers make the results of this diagnostic somewhat subjective.

\subsubsection{Luganda and Makhuwa}

Like most Bantu languages, Luganda and Makhuwa have a very limited inventory of adjectives, none of which can take complements.

For nominal arguments of nouns, a connective morpheme $-a$ is required in both languages, whereas nominal arguments of prepositions and verbs never require a connective or linker.

$$
\begin{array}{lll}
\text { (105) } & \text { ekifaananyi } *(\mathrm{ky}-\mathrm{a}) & \text { Joy } \\
\text { 7.picture } & \text { 7-CONN } & \text { 1.Joy } \\
\text { 'picture of Joy' } & \\
& & \\
\text { (106) } & \text { mapúrúrú *(a) } & \text { kwaátu } \\
\text { 6.fur 6.CONN } & \text { 1.cat } \\
\text { 'fur of the cat' } &
\end{array}
$$

This asymmetry superficially suggests that there is a licensing requirement in both languages, but, as mentioned, only to the extent that the connective morpheme functions only a nominal licenser.

However, the pattern (and the diagnostic) is undermined by the wider distribution of linkers in the two languages. As is well known, there is a continuum between possession and modification, with many languages using the same linguistic strategy for both (see Gil 2013, Nikolaeva \& Spencer 2012 for typological overviews). Specifically for the Bantu languages, Van de Velde (2013) shows that the connective morpheme is multifunctional in nominal modification, thus being similar to the ezafe construction. In short, it surfaces in many different kinds of nominal modification and seems to be unconnected to Vergnaud licensing. The multifunctionality in modification is illustrated for Makhuwa in (107).

$\begin{array}{ll}\text { (107) a. } & \text { ehantísí y-a khálái } \\ & \text { 9.story 9-CONN past.times } \\ \text { 'an old story' } & \\ \text { b. } & \text { ehópá y-a safáráwo } \\ & \begin{array}{l}\text { 9.fish 9-CONN yellow } \\ \text { 'a yellow fish' }\end{array}\end{array}$


c. nikúthá n-o-wóóceya

5.knee 5-CONN-be.tired.InF

'a tired knee' (Van der Wal 2009: 50)

The crucial question remains, nonetheless, whether the noun introduced by the linker is part of the argument structure of the modified noun (which would make the linker a case marker licensing the nominal complement of the noun, as Samiian 1994 and Larson and Yamakido 2008 argue for ezafe) or whether there is a different modification relation (as proposed by Ghomeshi 1997, Karimi 2007 for ezafe, and den Dikken and Singhapreecha 2004, den Dikken 2006, and Philip 2012 for linkers in general). Although it may be telling that the modifying element in these Bantu languages is always nominal, we find it difficult to conceptualise how 'yellowness' can be an argument of 'fish' that is merely licensed by the linker.

Furthermore, the connective morpheme also occurs in predication, which is unexpected if the connective were connected to Vergnaud licensing. ${ }^{40}$

$$
\begin{aligned}
& \begin{array}{llll}
\text { a. } & \text { Engoye } & \text { zi-no } & \text { ze } \\
& \text { 10.clothes } & 10-\text {-DEM } & 10 . \text { COP } \\
\text { 'These clothes are Paul's.' } \\
\text { b. } & & & \\
& \text { Ndi } & \text { w-a } & \text { kyenvu. } \\
& \text { 1SG.COP } & \text { 1-CONN } & \text { yellow }
\end{array} \\
& \text { 'I am yellow.'41 }
\end{aligned}
$$
a. O-hi-wury'
ésuúmú iyó, ti ya
Alí
2SG.SM-NEG-drink.OPT 9.juice 9.DEM COP 9-CONN 1.Ali
'Don't drink that juice, it's Ali's.'

[Luganda]
b. Ecanélá ti y' oótthúkúwa. 9.window COP 9.CONN 15.open 'The window is open.'

Given its multifunctionality (see Van de Velde 2013) and its use in predication, we take the connective construction in Luganda and Makhuwa not to reflect Vergnaud licensing.

Nevertheless, there is one environment in Makhuwa where the licensing of an NP argument in a nominal can be observed: non-subject relative clauses. Makhuwa relative clauses are best analysed as participles (Van der Wal 2010), that is, they are verbal up to a certain point (taking negation, tense and objects) but crucially function as nominals in the clause. This also entails that the subject of a non-subject relative in Makhuwa takes the possessive form: the participial can only license the subject by assigning genitive case to it, and the subject is encoded as possessive -aawe in (110).

\footnotetext{
${ }^{40} \mathrm{We}$ thank an anonymous reviewer for this suggestion.

${ }^{41}$ A more natural way of saying this is Nayenvuwadde 'I became banana-like'.
} 
(110) Maríá oo-wúryá

eleétí e-mwarish-aly-ááwé Alí

[Makhuwa]

1.Maria 1SM.PERF.DJ-drink 9.milk 9-pour-PERF-POSS.1 1.Ali

'Maria drank the milk which Ali poured' (Van der Wal 2010: 210)

This can be taken as evidence for the presence of Vergnaud licensing in Makhuwa: if nominals did not need licensing, the pronominal subject would be expected to come out as the personal pronoun yena, or the demonstrative ole, but not the possessive. In Luganda, no similar environment exists, as relative clauses are fully verbal, being introduced by a complementiser.

In conclusion, the postulated distinction between $\mathrm{V} / \mathrm{P}$ and $\mathrm{A} / \mathrm{N}$ in terms of their Case-assigning properties cannot straightforwardly be used as a diagnostic for Vergnaud licensing. If obligatory markers/linkers are related to merely licensing the overt appearance of an already present DP complement of $\mathrm{A} / \mathrm{N}$, this is evidence for the presence of Case. However, if such linkers perform other functions as well, such as the introduction of DP modifiers, the diagnostic is unreliable.

\subsection{Assignees}

In GB Theory it was also observed that in many languages DP complements to $\mathrm{N} /$ Adj necessitate the presence of a preposition or linker whereas $\mathrm{CP}$ complements do not. In Case Theory this was attributed to the idea that DPs require Case whereas CPs do not. Therefore, if a language shows an asymmetry between CP and DP complements, this can be taken as evidence for the presence of Case / Vergnaud licensing. In our sample, this diagnostic only gives a positive result for Jamaican Creole - but even then with a caveat. It is unreliable in Yoruba and Luganda, and not applicable in Mandarin and Thai (we have no data for Makhuwa), making this too a dubious diagnostic. This is unsurprising given that it also fails to be true in many more familiar languages (see Kayne 1975 on French, Plann 1986 on Spanish, Sheehan 2011 on English).

\subsubsection{Jamaican Creole}

Jamaican Creole is the only language with a clear result for this diagnostic, as it requires a marker for NP complements of adjectives (see (85) above) but not CP complements:

(111)Mi fried (se/dat) di enimi ago atak. 'I'm afraid (that) the enemy will attack.'

This is as expected if CPs do not need Case. However, the validity of this effect depends on the analysis of the linker/preposition, as discussed in 5.3.2. 


\subsubsection{Yoruba and Luganda}

At first sight, Yoruba also displays an asymmetry between DP/CP complements of nominalised stative verbs/adjectives, with only the former requiring an adposition:
a. bíbínú sí òtá náà being.angry to enemy the 'being angry at the enemy'
b. bíbínú pé ọ̀tá ti kọ lú wọ́n being.angry that enemy has attack them 'being angry that the enemy has attacked them'
(113) a. șísàníyàn nípa ojọo-iwájú
being.anxious about future 'being anxious about the future'

b. șísàníyàn pé òtá máa ko lù wọ́n being.anxious that enemy will attack them 'being anxious that the enemy will attack them'

However, both CP and DP complements of nouns are introduced by linkers, as shown in (114), and the linkers can even sometimes surface in examples like (112b) and (113b).
(114) a. Ìrètí i pé òjò máa rò̀ (și wà) [Yoruba] hope LNK that rain will fall still exist
b. Bàbá a Báyò̀
father LNK Bayo
'Bayo's father'

There is thus no difference between CP and DP complements of nouns, and the unclear status of the linker renders the result of this diagnostic unreliable for Yoruba.

Luganda requires a connective marker for DP complements of nouns but not for CPs. As mentioned in 5.3.3 above, we do not take the connective to be related to Vergnaud licensing I this language, making this diagnostic irrelevant.

(115) okutuuka kw-a Yesu Kristu

[Luganda]

15.arrive 15-CONN Jesus Christ

'the arrival/arriving of Jesus Christ'

(116) Eky' okuba nti Martin mutuufu ki-nyiiza.

7.REL? 15.be COMP 1.Martin right.one 7SM-annoying

'The fact that Martin is right is annoying.' 
Olugambo mbu a-kozesa ebiragala lu-m-pisa bu-bi.

11.rumor hearsay.COMP 1SM-use 8.drugs 11SM-1SG.SM-treat 14-bad

'The rumor that he is a drug addict makes me stressed.'

\subsubsection{Mandarin and Thai}

In Mandarin, genuine adjectives do not appear to accept clausal complements and neither do nouns, rendering this diagnostic inapplicable. ${ }^{42}$

Thai does not have adjectives taking CP complements, and it is questionable whether Thai has CP complements of nouns either. Jenks (2011, 2014) argues that CPs attached to nouns are adjuncts, rather than complements, partly based on the fact that the 'complement' is required to follow the relative clause in (118).

$$
\begin{aligned}
& \text { a. Chăn mày chûuə [NP khàaw-lu廿 } \\
& \text { 1SG NEG believe rumor } \\
& \text { [RC thîi chăn dây-yin mutə-chaaw-níi] } \\
& \text { THÎI 1SG hear time-morning-this } \\
& \text { [CP thîi wâa khăw cà yáay bâan.] ] } \\
& \text { THÎI COMP } 3 \text { PROSP move house }
\end{aligned}
$$

'I don't believe the rumor that I heard this morning that he'll move.'

b. * Chăn mày chûuə [NP khàaw-luu 1SG NEG believe rumor

[cP thîi wâa khăw cà yáay bâan]

THÎI COMP 3 PROSP move house

[Rc thîi chăn dây-yin muயə-chaaw-níi.]

THÎI 1SG hear time-morning-this

'I don't believe the rumor that he'll move that I heard this morning.'

(Jenks 2014: 313)

Jenks concludes that the thîi-marked 'complement' is more like a nominal modifier. The marker thîi can then be analysed as a relative complementiser, as suggested in the translations in (119), or as a type-shifter which makes a predicate of the $\mathrm{CP}$, as Jenks argues.

Khôjthétcin (thîi) wâa maatin pen fàaj thùuk nán
nâa.ramkhaan.

fact REL COMP/SAY ${ }^{43}$ MartinCOP side right DEM likely.annoy 'The fact (which) that Martin is right is annoying.'

[Thai]

In summary, the reliability of this diagnostic depends on the status of the relevant linkers in the languages under discussion, and is in the majority of languages either inapplicable or unreliable. Only in Jamaican Creole do we find some suggestive evidence of a CP/DP asymmetry of the kind that has been

\footnotetext{
${ }^{42}$ Nouns can in Mandarin, though, be modified by relative clauses introduced by the linker $d e$ ( $\mathrm{Li}$ 1985, 1990). As discussed in footnote 8, it seems problematic to take de to be a Case-assigner.

${ }^{43}$ wâa is a complementiser that is grammaticalising/has grammaticalised from the verb 'to say'. An alternative structure and translation could thus be 'The fact that says Martin is right is annoying'.
} 
attributed to Vergnaud licensing. Moreover, given the patterns in more familiar languages, which are less controversially taken to have Vergnaud licensing, it seems unlikely that there is a hard and fast DP/CP distinction of this kind more generally.

\subsection{Summary of less reliable diagnostics}

In this section we have reviewed diagnostics six to nine and argued that while in some cases they are suggestive, they are, in general, less reliable as diagnostics of Vergnaud licensing. The problems with taking morphological case as a diagnostic for Vergnaud licensing are manifest and have been apparent throughout this paper. The diagnostic concerning anaphors faces the problem that it fails to pick out the right class of languages whether it concerns morphological agreement or Agree dependencies established for the purpose of Vergnaud licensing. Finally, the last two diagnostics also raise certain problems. In some instances, it is difficult to find independent evidence for the class of adjectives vs. verbs or even for nouns vs. adpostions and the presence in many of our languages of linkers in a wide range of contexts makes it seem unlikely that their presence if entirely due to Vergnaud licensing. Also, with the exception of Jamaican Creole, there does not seem to be a clear division whereby DPs but not CPs require licensing. This is unsurprising, given that this pattern fails to hold even in some wellstudied European languages, arguably including French (Kayne 1975), Spanish (Plann 1986) and English (Sheehan 2011). The conclusion is that while there is a cluster of properties which seems to pattern together in our sample in distinguishing Luganda from the other languages, it is a smaller cluster of properties than those traditionally attributed to Vergnaud licensing.

\section{Summary of results and discussion}

The preceding discussion has taken nine purported diagnostics for Vergnaud licensing and applied them to four analytic languages which, on the surface, might be expected to lack nominal licensing, as they lack both case and agreement morphology. Relating these results back to the contrast between the Bantu languages Makhuwa and Luganda discussed in section 3, it is striking that there is no evidence for the lack of Vergnaud licensing in any of these languages. To the extent that the diagostics are reliable, they show that all four of the analytic languages pattern with Makhuwa rather than Luganda in requiring DPs to be licensed. This may, of course, be an accident of the sample and further work should be carried out on other analytic languages to ascertain whether any such languages pattern with Luganda and the other Bantu languages discussed by Diercks (2012). An interesting possibility, though, is that the paramerisation Diercks describes might only be available in languages with rich agreement, so that Vergnaud licensing applies as the default even in caseless languages. In any case, it clearly holds that there are caseless languages with a nominal licensing requirement. This is, of course, unsurprising on a view which divorces morphological case from Vergnaud licensing, but it serves to further highlight that the correct analysis of this effect is not best modeled in terms of uninterpretable Case features. 
With respect to methodological issues, several challenges have arisen in the course of the above cross-linguistic investigation. As Baker \& McCloskey (2007) note, when comparing typologically and genetically distinct languages, considerable care is required and diagnostics must be adjusted and adapted substantially. When this is done, however, we see that diagnostics 1-5 do seem to cluster together and can be used to diagnose requirement for Vergnaud licensing. Diagnostics 6-9, on the other hand, are more problematic for a variety of reasons, as summarised in section 5.5.

\begin{tabular}{|l|l|l|l|l|l|l|}
\hline & Mandarin & Thai & Yoruba & JC & Makhuwa & Luganda \\
\hline 1. Non-finite clauses & + & + & + & + & + & - \\
\hline 2. Agreement & n.a. & n.a. & n.a. & n.a. & + & - \\
\hline 3. Activity & + & + & + & + & + & - \\
\hline 4. Passive agent & n.a. & n.a. & n.a. & + & + & - \\
\hline 5. Case-based asymmetry & 0 & 0 & + & + & 0 & 0 \\
\hline 6. Morphology & 0 & 0 & + & 0 & 0 & 0 \\
\hline 7. Anaphors & - & - & + & + & n.a. & n.a. \\
\hline 8. Assigners (A/N vs. V/P) & + & + & $+?$ & $+?$ & + & 0 \\
\hline 9. Assignees (CP vs. DP) & n.a. & n.a. & $+?$ & $+?$ & $?$ & $?$ \\
\hline
\end{tabular}

Table 4: All diagnostics (+ evidence of Vergnaud licensing, - evidence for lack of Vergnaud licensing , 0 compatible with either, n.a. test cannot be applied, ? no data or unclear)

Given the exceptional behaviour of Luganda in our current sample (and the other Bantu languages Diercks discusses), it is actually attractive to reject the simple parameterization account and entertain the possibility that the nominal licensing requirement is universal, but that languages like Luganda license nominals by some different (Bantu-specific) means. We explore this possibility in the following section before also assessing the broader theoretical import of our findings.

\subsection{Rethinking the Bantu parameter}

The diagnostic data from Luganda (and the languages studied by Diercks 2012) suggest that Vergnaud licensing does not play a role in these Bantu languages. Nevertheless, the distribution of DPs is not totally unrestricted Luganda. To illustrate, consider Zulu and Luganda nominals. In both languages nominals can come in either of two forms: with or without the so-called augment (also referred to as the initial vowel). Halpert $(2013,2015)$ shows for Zulu that nominals that lack the augment (muntu vs. $u$-muntu) have a very restricted distribution, similar to that of bare NPs in Romance languages: ${ }^{44}$ augmentless nominals are licensed under negation, and only within the vP domain, whether in the lower or the higher clause, as illustrated in (120).

\footnotetext{
${ }^{44}$ Progovac (1993) and Carstens \& Mletshe (to appear) in fact propose an analysis of augmentless nominals as NPIs.
} 
b. * A-ngi-fun-i [ukuthi muntu a-pheke iqanda]. NEG-1SG.SM-want-NEG that 1.person 1SM.SJ-cook5.egg

c. A-ngi-fun-i muntu [ukuthi $_{\mathrm{i}}$ a-pheke iqanda]. NEG-1SG.SM-want-NEG 1.person that 1SM.SJ-cook 5.egg 'I don't want anyone to cook an egg.' (Zulu, Halpert 2012)

The contrast between (121a-b) shows that it is not sufficient for augmentless nominals to be in the scope of negation, they must also be contained in a vP, either by virtue of being an unaccusative subject or by raising to a higher vP. The same appears to hold for Luganda, where initial research also suggests that augmentless nominals must be vP-internal. In Luganda, augmentless nouns are licensed not only by negation but also by focus, regardless of negation (Hyman and Katamba 1993). DPs can never be augmentless in preverbal subject position or in left- or right-dislocated positions, suggesting a restriction to the clauseinternal low domain (vP). Further evidence for this internal position is the fact that postverbal patients and recipients can be augmentless [-A] when in the same domain as the verb, but an augmentless noun cannot follow an augmented noun $[+A]$, as shown in (121c).

(Luganda, Hyman and Katamba 1993: 228-229)

This pattern would follow if something akin to Agree regulates the distribution of augmentless but not augmented nominals. In a model which permits multiple Agree, the patterns in (121a and d) follow straightforwardly. The difference between (121b-c) follows if augmented DPs act as defective interveners for the licensing of augmentless nominals, as such an augmentless nominal cannot be embedded lower than a vP-internal augmented DP, but the reverse is unproblematic.

Likewise, postverbal agents in locative inversion (122) and passives (123) can also be augmentless (Namyalo and Van der Wal 2014). These agents are in-situ (Pak 2008), as evidenced by the verbal negation scoping over the quantified subject in (123): the reported interpretation is $\mathrm{Neg}>\forall$. 
'It's a mad person who sleeps here.'(nobody else)
(123) E-bi-tabo
bi-no
te-bi-som-w-a
ba-izi
b-onna.
8A-8PX-books 8-DEM NEG-8SM-read-PASS-FS 2PX-students 8-all 'These books are not read by all students.'

The implication seems to be that there is evidence for some kind of nominal licensing in Zulu and Luganda but that this mechanism is distinct from that observed in other languages (where it is connected to grammatical functions).

In the case of Zulu, Halpert $(2012,2015)$ defends the universality of Vergnaud licensing and suggests that independent facts about the internal structure of Zulu DPs make licensing opaque in many contexts. She proposes that in Zulu the augment serves to inherently license DPs - possibly equivalent to DPs marked with inherent Case (KP), which also do not require licensing in some languages (McFadden 2015, Caha 2009). ${ }^{45}$ This DP-internal licensing thus distinguishes Zulu and Luganda from languages that do show the effects of Vergnaud licensing. To account for the restricted distribution of augmentless nominals in Zulu, Halpert proposes that there is only one licensing head in Zulu, $\mathrm{L}$, which sits just above vP. This account for the fact that augmentless nominals are not licensed outside of vP (the contrast between (136a-b) shows that this not just because they function as NPIs).

For Luganda this licensing head would need to be associated with focus. This is similar to the licensing of a postverbal subject in Xhosa transitive expletive constructions, which Carstens and Mletshe (2015) propose is due to a Focus head just above vP. All of this shows the uncomfortable fit between Bantu syntax and traditional Vergnaud-licensing.

An alternative is to abandon the grammatical function-based notion of nominal licensing (i.e. traditional abstract Case or what we have referred to as Vergnaud licensing) and search for an alternative nominal licensing system in these languages. Since information structure is known to play a pervasive role in the syntax of Bantu languages (Downing \& Hyman 2015, Van der Wal 2015c, Güldemann et al. 2015), the alternative licensing system might be hypothesised to be based upon one or more categories in information structure. For example, argument indexing on the verb and movement to the preverbal position need not be related to subject licensing: The preverbal position in many Bantu languages has been argued to be restricted to topical/non-focal elements (see, among others, Bokamba 1967, Morimoto 2000, Sabel and Zeller 2006, Zerbian 2006, 2007, Van der Wal 2009, Yoneda 2011), and "subject" agreement has been argued to be directly related to topicality (Morimoto 2006 for Kirundi), or indirectly via the requirement to agree with a higher, preverbal element (Baker 2003, 2008, Collins 2004, Carstens 2005, Diercks 2011). We leave to future research the details of such an alternative licensing system, its relation with Vergnaud licensing, and its variation in further Bantu languages.

\footnotetext{
${ }^{45}$ Note that this is the opposite of Baker (2003) who suggests that augmentless nouns in Kinande do not need to be Case licensed, and of Carstens and Mletshe (to appear) for Xhosa.
} 


\subsection{PRO, finiteness and Vergnaud licensing}

Reviewing once more our results, it is certainly striking that in the analytic languages that we have discussed, most of which lack passives, there are only really three reliable diagnostics and only two that apply to all of the languages in question: the ban on overt referential subjects in non-finite clauses (diagnostic 1 ) and the lack of hyperactivity (diagnostic 3). Neither of these diagnostics is without problems, even in languages with morphological case and both of them relate to the distribution of PRO/trace, a highly controversial topic, mired in controversy.

\begin{tabular}{|l|l|l|l|l|l|l|}
\hline & Mandarin & Thai & Yoruba & JC & Makhuwa & Luganda \\
\hline 1. Non-finite clauses & + & + & + & + & + & - \\
\hline 2. Agreement & n.a. & n.a. & n.a. & n.a. & + & - \\
\hline 3. Activity & + & + & + & + & + & - \\
\hline 4. Passive agent & n.a. & n.a. & n.a. & + & + & - \\
\hline 5. Case-based asymmetry & 0 & 0 & + & + & 0 & 0 \\
\hline
\end{tabular}

Table 5: Reliable diagnostics (+ evidence of Vergnaud licensing, - evidence for lack of Vergnaud licensing , 0 compatible with either, n.a. test cannot be applied, ? no data or unclear)

Diagnostic 3 is challenged by copy raising and hyperraising in languages with and without morphological case. In fact, three of our analytic languages also have copy raising and none has clear evidence of raising. While the evidence suggests that copy raising does not actually involve movement (the 'absent chef'test discussed above), the virtual lack of true raising in the languages under discussion remains striking and potentially problematic. This is all the more the case because it means that we are reduced to control contexts to use as evidence, and there are alternative accounts of control that do not attribute it to nominal licensing.

In fact, diagnostic 1 faces significant challenges in well-studied languages. Icelandic, once again, is relevant as a language in which it can be shown that PRO can have a morphological case distinct from that of its controller (Thráinsson 1979, Sigurðsson 2008, Bobaljik \& Landau 2009 amongst many others). These well-known facts raise yet more challenges for the analysis of morphological case in Icelandic and provide further evidence that it is not directly connected to Vergnaud licensing. In fact, it has been questioned whether the distribution of PRO is best analysed as an effect of Vergnaud licensing at all. Russian shows essentially the same effect (Landau 2008), as does European Portuguese (Sheehan 2015a).

It has long been noted that it is problematic to assume that PRO, the null subject of non-finite clauses, lacks Case (see Landau 2006 for a summary of the discussion). An obvious challenge comes from the fact that in some languages PRO seems to have Case, or at least case (DAT in Russian, NOM in European Portuguese), as can be observed through secondary predication or agreement on inflected infinitives respectively:

(124) Ona poprosila ego [PRO ne ezdit tuda odnomu].
she.NOM asked 
'She asked him not to go there alone.' [Russian, Landau (2008: 883)]

(125) 0 Pedro prometeu à Ana [PRO reunirem=se em Braga] the Pedro promised to.the Ana PRO meet.3PL=SE in Braga 'Pedro promised Ana to meet in Braga.' [E. Portuguese, Sheehan (2014: 118)]

Such facts show that, in some contexts, referential DPs are ruled out, despite the availability of Case, raising some problems for Case-based accounts of Control.

Landau (2004) proposes an alternative account for the distribution of PRO which attributes it to the nature of I in the host clause. According to his Control Calculus, I is specified as +/-Agr and +/-T leading to the Obligatory Control-No Control (OC-NC) generalisation is as follows (Landau 2014: 10):

(126) The OC-NC Generalization

In a fully specified complement clause (i.e., the $\mathrm{I}^{0}$ head carries slots for both [T] and $[$ Agr $]$ :

a. If $\mathrm{I}^{0}$ carries both semantic tense and agreement ([+T,+Agr]), NC obtains.

b. Elsewhere, OC obtains.

The problem with this descriptive generalisation in relation to agreemenless languages like most of those in the current paper is that either (a) if we take morphology seriously, then all clauses are [-Agr] hence should be OC contexts, contrary to fact or (b) we are forced to posit covert [+Agr] in non-control contexts in an entirely circular fashion. ${ }^{46}$ In fact, what we find is a clear split in these agreementless languages whereby only those contexts which can be independently diagnosed as non-finite require obligatory OC.

An alternative possibility, then, is to assume that in such languages, there is no [+/-Agr] specification so that what is relevant is merely [+/-T], with [+T] (diagnosed in the language-specific manners described above) being the NC context and [-T] leading to OC. The problem with this account, though, is that it still cannot account for the Luganda pattern. Why would it be that in Luganda, a language with [+/-Agr], some [-Agr] contexts would be a viable host for a referential DP? Landau's Control Calculus therefore has no way of explaining the Luganda pattern, unless it is to be parameterised in surprising ways. It seems that we still need nominal licensing as an explanatory factor in our analysis of control, even if it is not the whole story.

While the simple biconditional relation between nominal licensing and referential DPs fails, a one-way implication nonetheless holds in this domain:

${ }^{46}$ The same is true of Landau's (2014) revised OC-NC generalization:

(i) The OC-NC Generalization (restated)

[+Agr] blocks control in attitude complements but not in non-attitude complements. Or:

[+Agr] blocks logophoric control but not predicative control.

Again, this makes unclear predictions for languages lacking agreement and also fails to be able to accommodate the Luganda pattern. 
(127) If a given subject position is not Vergaud licensed, then an overt referential DP is not allowed. ${ }^{4}$

The fact that this implication holds only in one direction can be attributed to the fact that there appear to be two distinct kinds of obligatory control (OC), both within and across languages - see Cinque (2006), van Urk (2010), as well as Grano (2012), Sheehan $(2014,2015 a)$. In one kind of OC, which we call exhaustive OC (observed with Icelandic and Russian case transmission and EP uninflected infinitives), the exhaustively controlled subject has the properties of a trace and the dependency may possibly be derived via A-movement (as proposed by Hornstein 1999). In the other kind of control, which we call pro OC, (observed with Icelandic and Russian case independence and EP inflected infinitives), the partially/exhaustively controlled subject does not behave like a trace but rather has its own features and is arguably Vergnaud-licensed, favouring an Agree-based account (roughly along the lines suggested by Landau 2000,2004 , et seq., see also Sheehan 2015a). Exhaustive OC has only an exhaustive reading, whereas pro OC permits also a partial control reading, all else being equal (see Sheehan 2016). In the case of Exhaustive OC, the impossibility of an overt referential subject and the necessity of a control reading is explained by the lack of licensing and the necessity of A-movement (Hornstein 1999). However, in the case of pro OC the ban on an overt referential subject is due to other factors (Sheehan 2016 argues that the position of the controlled pro is crucial).

In terms of our diagnostics, this means that we cannot straightforwardly take a ban on overt referential DPs in non-finite OC contexts as evidence for Vergnaud licensing. Only a thorough investigation of the properties of OC in a given language can reveal for certain whether we are dealing with exhaustive OC or pro OC. At least in Mandarin, however, it seems that we are indeed dealing with the first kind of OC. Grano (2012: ch5) shows that only exhaustive OC is found in Mandarin, in the complements of what Landau labels exhaustive control predicates. This is somewhat unsurprising. Given the lack of inflectional morphology in Mandarin it is difficult to see how a child could detect the availability of Vergnaud licensing in such contexts if overt referential subjects are systematically banned. A plausible hypothesis, then, is that these languages only have exhaustive $\mathrm{OC}$, though this remains to be verified. While this topic clearly merits further research, it is striking that all of the languages except Luganda limit overt referential subjects to finite contexts (where finite is defined in independent language-specific ways). Given the parameterisation observed, Vergnaud licensing (however it is formalised) remains the best explanation for this fact at present.

\footnotetext{
${ }^{47}$ Note that the reverse that 'if PRO is licensed then Vergnaud licensing does not hold' cannot be maintained in the light of Icelandic, Russian and EP (see also Sundaresan and McFadden 2009, Sundaresan 2014). We refer to overt referential DPs here as it has been shown that in a number of languages, overt focused pronominals are licensed in control contexts, so the opposition is not simply between overt and covert subjects (see Szabolszi 2009, Barbosa 2009).
} 


\section{Conclusions}

In this paper we have taken nine potential diagnostics for Vergnaud licensing (abstract Case) and applied them to a number of languages without case and/or agreement morphology. Only five of these diagnostics turn out to be reliable indicators, suggesting that of the six languages under discussion only one, Luganda, consistently fails to show evidence for Vergnaud licensing. This parameterisation and the clustering of properties related to licensing require an explanation that we suggest should go beyond the traditional account in terms of abstract Case. We note also, in this regard, that many recent theories of case concern only morphological case marking, leaving aside the phenomenon of Vergnaud licensing. Nonetheless, the requirement for nominal licensing remains a pervasive feature of human languages.

Many questions remain for future research of course. What is the connection between (non-)finiteness and nominal licensing/PRO? What kind of Control is found in the languages under discussion? Why are passives unavailable in most of the languages under discussion? What is the explanation for the ban on nominative anaphors in Yoruba and Jamaican Creole and more generally? What is the function of the linker? What is the correct analysis of hyperraising and copy raising and how does this relate to nominal licensing more generally? Is there an alternative, possible discourse-driven, licensing system available in languages that test negative for Vergnaud licensing?

It is also vital that the discussed diagnostics are applied to further analytic languages beyond our sample. Recent research has shown the necessity and value of carrying out further systematic microcomparative research in Bantu languages. On a broader macrocomparative level we would like to find a nonBantu language patterning like Luganda (see footnote 5). Testing of this kind will reveal whether the apparent clustering of the 'nominal licensing property' is robust cross-linguistically. With the increased interest in Dependent Case theory (Marantz 1991, Baker 2015) and the distinction between the realisation of case ("M-case") and some abstract licensing mechanism ("Vergnaud licensing", Pesetsky 2014), a reconsideration of this kind has become ever more pressing.

Finally, it is important that future work develops a more explanatory account of the nominal licensing requirement. Given the divorce between morphological case/agreement and abstract licensing, it seems likely that this explanation will not be formulated in terms of [Case] features. See Sheehan and van der Wal (2016) for the sketch of such an account.

\section{References}

Aissen, Judith. 2003. Differential object marking: iconicity vs. economy. Natural Language \& Linguistic Theory 21, 435-483.

Abney, Steven P. 1987. The English noun phrase in its sentential aspect. Cambridge, MA: MIT dissertation.

Adesola, Oluseye. 2005. Pronouns and Null Operators - A-bar Dependencies and Relations in Yoruba. New Brunswick, NJ: Rutgers Dissertation.

Adger, David \& Daniel Harbour. 2007. Syntax and syncretisms of the Person Case Constraint. Syntax 10. 2-37. 
Ajíbóyè, Oládiípò, Rose-Marie Déchaine, Bryan Gick \& Douglas Pulleyblank. 2011. Disambiguating Yorùbá Tones: At the Interface between Syntax, Morphology, Phonology and Phonetics. Lingua 121, 1631-48.

Aldridge, Edith. 2004. Ergativity and word order in Austronesian languages. Ithaca, NY: Cornell University dissertation.

Aldridge, Edith. 2008. Generative approaches to ergativity. Languages and Linguistics Compass: Syntax and Morphology 2 (5), 966-995.

Alexiadou, Artemis \& Elena Anagnostopoulou. 2002. Raising without Infinitives and the Nature of Agreement. In Artemis Alexiadou, Elena Anagnostopoulou, Sjef Barbiers and Hans-Martin Gärtner (eds.), Dimensions of Movement, 1731. Amsterdam: John Benjamins.

Anderson, Stephen. 1976. On the notion of subject in ergative languages. In Charles N. Li (ed.), Subject and Topic, 1-24. New York: Academic press.

Anderson, Stephen. 1982. Types of dependency in anaphors: Icelandic (and other) reflexives. Journal of Linguistic Research 2, 1-22.

Andrews, Avery D. 1976. The VP-complement analysis in Modern Icelandic. In Joan Maling \& Annie Zaenen (eds.), NELS 6: proceedings of the 6th meeting of the North Eastern Linguistic Society, 1-21. Amherst: GLSA. [Reprinted in Joan Maling \& Annie Zaenen (eds.), Modern Icelandic syntax, 165-185. San Diego: Academic Press.

Asudeh, Ash \& Ida Toivonen. 2006. Expletives and the syntax and semantics of copy raising. In Miriam Butt \& Tracy Holloway King (eds.), Proceedings of the LFG06 Conference, 13-29. Stanford, CA: CSLI Publications.

Asudeh, Ash \& Ida Toivonen. 2012. Copy raising and perception. Natural Language and Linguistic Theory 30(2), 321-380

Baker, Mark \& Jim McCloskey. 2007. On the relationship of typology to theoretical syntax. Linguistic Typology 11, 285-96.

Baker, Mark. 2003. Lexical categories: Verbs, nouns, and adjectives. Cambridge: Cambridge University Press.

Baker, Mark. 2008. The syntax of agreement and concord. Cambridge: Cambridge University Press.

Baker, Mark. 2015. Case: Its principles and its parameters. Cambridge: Cambridge University Press.

Bamgboșe, Ayọ. 1966. A Grammar of Yoruba. Cambridge: Cambridge University Press.

Bárány, András. 2015. Differential object marking in Hungarian and the morphosyntax of case and agreement. Cambridge: University of Cambridge dissertation.

Barbosa, Pilar. 2009. A Case for an Agree-based Theory of Control. In Sun-Woong Kim (ed.), Proceedings of the 11th Seoul International Conference on Generative Grammar, 101-123. Seoul: Hankuk Publishing Company.

Belletti, Adriana. 1988. The case of unaccusatives. Linguistic Inquiry 19, 1-34.

Bhat, D. N. S. \& Regina Pustet. 2000. Adjective. In Geert Booij, Christian Lehmann \& Joachim Mugdan (eds.), Morphology: An international handbook on wordformation, 757-770. Berlin: Mouton de Gruyter.

Biggs, Alison. 2014. Dissociating Case from theta-roles: A comparative investigation. Cambridge: University of Cambridge dissertation.

Bobaljik, Jonathon \& Idan Landau. 2009. Icelandic control is not A-movement: the case from case. Linguistic Inquiry 40.113-132. 
Brame, Michael. 1977. Alternatives to the Tensed S and Specified Subject Conditions. Linguistics and Philosophy 1, 381-411.

Carstens, Vicki. 1986. Proper Government in Yoruba. Los Angeles, CA.: UCLA MA Thesis.

Carstens, Vicki. 1987. On Empty Categories and phonological rules. Unpublished manuscript, UCLA and Yale University.

Carstens, Vicki. 2005. Agree and EPP in Bantu. Natural Language and Linguistic Theory 23, 219-279.

Carstens, Vicki. 2011. Hyperactivity and Hyperagreement in Bantu. Lingua 121(5), 721-41.

Carstens, Vicki \& Michael Diercks. 2013. Parameterizing Case and Activity: Hyper-raising in Bantu. In Seda Kan, Claire Moore-Cantwell \& Robert Staubs (eds.), Proceedings of the 40 ${ }^{\text {th }}$ Annual Meeting of the North East Linguistic Society (NELS), 99-118. Amherst: GLSA.

Carstens, Vicki \& Loyiso Mletshe. To appear. N-words in disguise: a negative concord approach to augmentless NPIs in Xhosa and Zulu. Natural Language and Linguistic Theory.

Carstens, Vicki \& Loyiso Mletshe. 2015. Radical defectivity: Implications of Xhosa expletive constructions. Linguistic Inquiry 46(2), 187-242.

Chomsky, Noam. 1981. Lectures on government and binding. Dordrecht: Foris Publications.

Chomsky, Noam. 1995. The Minimalist Program. Cambridge, MA: MIT Press.

Chomsky, Noam. 2000. Minimalist Inquiries: The Framework. In Roger Martin, David Michaels \& Juan Uriagereka (eds.), Step by Step. Essays on Minimalist Syntax in Honour of Howard Lasnik, 89-155. Cambridge, MA: MIT Press.

Chomsky, Noam. 2001. Derivation by phase. In Michael Kenstowicz (ed.), Ken Hale: a life in language, 28-53. Cambridge, MA: MIT Press.

Cinque, Guglielmo. 2006. Restructuring and functional heads. Oxford \& New York: Oxford University Press.

Coon, Jessica. 2013. Aspects of Split Ergativity. New York: Oxford University Press.

Coon, Jessica, Pedro Mateo Pedro \& Omer Preminger. 2015. The Role of Case in A-Bar Extraction Asymmetries: Evidence from Mayan. Linguistic Variation $14(2), 179-242$.

Cowper, Elisabeth. 2002. Finiteness. Unpublished manuscript, University of Toronto.

Dalrymple, Mary \& Irina Nikolaeva. 2011. Objects and Information Structure. Cambridge: Cambridge University Press.

Deal, Amy Rose. 2015. Ergativity. Submitted to International Handbook on Syntactic Contemporary Research, 2nd edition. Artemis Alexiadou and Tibor Kiss. [available at: lingbuzz/001624]

Déchaine, Rosemary. 2001. On the Left Edge of Yoruba Complements. Lingua 111, 81-130.

Diercks, Michael. 2011. The morphosyntax of Lubukusu locative inversion and the parameterization of Agree. Lingua 121(5), 702-720.

Diercks, Michael. 2012. Parameterizing Case: Evidence from Bantu. Syntax 15(3), 253-86.

de Hoop, Helen \& Peter de Swart (eds.). 2008. Differential Subject Marking. Studies in Natural Language and Linguistic Theory. Dordrecht: Springer. 
den Dikken, Marcel \& Pornsiri Singhapreecha. 2004. Complex Noun Phrases and Linkers. Syntax 7(1), 1-54.

den Dikken, Marcel. 2006. Relators and linkers. The syntax of predication, predicate inversion, and copulas. Cambridge, MA: MIT Press.

Douglas, Jamie \& Michelle Sheehan. 2016. Two ways to be high ABS: on avoiding defective intervention. Poster presented at Generative Linguistics in the Old World (GLOW), April 2016.

Durrleman-Tame, Stephanie. 2008. The Syntax of Jamaican Creole. Amsterdam: John Benjamins.

Erlewine, Michael Yoshitaka. 2014. Why the null complementizer is special in the English that-trace effect. Unpublished ms. MIT.

Erlewine, Michael Yoshitaka. 2016. Anti-locality and Optimality in Kaqchikel Agent Focus. Natural Language \& Linguistic Theory, 34(2), 429-479.

Everaert, Martin. 1991. Nominative anaphors in Icelandic: morphology or syntax? In Werner Abraham, Wim Kosmeijer \& Eric Reuland (eds.), Issues in Germanic syntax, 277-305. Berlin: Mouton de Gruyter.

Ferreira, Marcelo. 2004. Hyperraising and Null Subjects in Brazilian Portuguese. MIT Working Papers in Linguistics 47: Collected Papers on Romance Syntax, 57-85.

Filbeck, David. 1973. The Passive in Thai. Anthropological Linguistics 15(1), 3341.

Fisher, Karen. 1988. Agreement and the distribution of anaphors. In Michael Hammond, Edith Moravcsik \& Jessica Wirth (eds.), Studies in syntactic typology, 25-36. Amsterdam: John Benjamins.

Ghomeshi, Jila. 1997. Non-projecting nouns and the ezafe construction in Persian. Natural Language \& Linguistic Theory 15, 729-88.

Gil, David. 2013. Genitives, adjectives and relative clauses. In Matthew S. Dryer \& Martin Haspelmath (eds.), The World Atlas of Language Structures Online. Leipzig: Max Planck Institute for Evolutioanry Anthropology.

Grano, Thomas. 2012. Control and restructuring at the syntax-semantics interface. Chicago, IL: University of Chicago dissertation.

Grimshaw, Jane. 1990. Argument structure. Cambridge, MA: MIT Press.

Güldemann, Tom, Sabine Zerbian \& Malte Zimmermann. 2015. Variation in Information Structure with Special Reference to Africa. Annual Review of Linguistics 1 (1), 155-178.

Haegeman, Liliane. 1985. INFL, COMP and nominative Case assignment in Flemish. In Henk van Riemsdijk \& Pieter Muysken (eds), Features and projections, 123-137. Dordrecht: Foris.

Halpert, C., 2013. Structural case and the nature of vP in Zulu. In Shayne Sloggett \& Stefan Keine (eds.), Proceedings of the 42nd Meeting of the North East Linguistic Society (NELS 42).

Halpert, Claire. 2015. Argument licensing and agreement. Oxford: Oxford University Press.

Harford Perez, Carolyn. 1985. Aspects of complementation in three Bantu languages. University of Wisconsin-Madison dissertation.

Haspelmath, Martin. 2010. Comparative concepts and descriptive categories in crosslinguistic studies. Language 86 (3), 663-687.

Haspelmath, Martin \& König, Ekkehard (eds). 1995. Converbs in Cross-Linguistic Perspective: Structure and Meaning of Adverbial Verb Forms - Adverbial 
Participles, Gerunds. Empirical approaches to language typology 13. Berlin: Mouton de Gruyter.

Heine, B. 2000. Polysemy involving reflexive and reciprocal markers in African languages. In Zygmunt Frajzyngier \& Tracy S. Curl (eds.), Reciprocals: forms and functions, 31-62. Amsterdam: John Benjamins.

Henderson, Brent. 2006. Multiple agreement, concord and case checking in Bantu. In Olaoba F. Arasanyin \& Michael A. Pemberton, Selected Proceedings of the 36th Annual Conference on African Linguistics, 60-65. Somerville, MA: Cascadilla Proceedings Project.

Hornstein, Norbert. 1999. Movement and Control. Linguistic Inquiry 30, 69-96.

$\mathrm{Hu}$, Jianhua, Haihua Pan \& Liejiong Xu. 2001. Is there a finite vs. nonfinite distinction in Chinese? Linguistics 39, 1117-48.

Huang, Cheng-Teh James. 1982. Logical relations in Chinese and the theory of grammar. Cambridge, MA: MIT dissertation.

Huang, Cheng-Teh James. 1984. On the distribution and reference of empty pronouns. Linguistic Inquiry 15, 531-574.

Huang, Cheng-Teh James. 1989. Pro-drop in Chinese: a generalized control theory. In Osvaldo Jaeggli \& Ken Safir (eds.), The null subject parameter, 185214. Dordrecht: Kluwer Academic Publishers.

Huang, Cheng-Teh James. 1999. Chinese Passives in Comparative Perspective. Tsing Hua Journal of Chinese Studies 29, 423-509.

Huang, Cheng-Teh James, Li, Yen-hui Audrey \& Yafei Li. 2009. The syntax of Chinese. Cambridge: Cambridge University Press.

Huang, Shi-Zhe and Peter Jenks. 2013. Nominal modification in Chinese and Thai. In Robert E. Santana-LaBarge (ed.), Proceedings of WCCFL 31, 227-237. Somerville, MA: Cascadilla Proceedings Project.

Hyman, Larry M. \& Francis X. Katamba. 1993. The augment in Luganda: syntax or pragmatics? In Sam Mchombo (ed.), Theoretical aspects of Bantu grammar, 209-256. Stanford: CSLI.

Iatridou, Sabine. 1993. On nominative Case assignment and a few related things. MIT Working Papers in Linguistics 19, 175-96.

Iorio, David. 2014. Subject and object marking in Bembe. Newcastle: Newcastle University dissertation.

Jelinek, Eloisie and Andrew Carnie. 2003. Argument hierarchies and the mapping principle. In Andrew Carnie et al. (eds.), Formal Approaches to Function in Grammar. Amsterdam/Philadelphia: John Benjamins. 265-296.

Jenks, Peter. 2006. Control in Thai. Ms, University of California, San Diego.

Jenks, Peter. 2011. The Hidden Structure of Thai Noun Phrases. Cambridge, MA: Harvard University dissertation.

Jenks, Peter. 2014. Generalized clausal modifiers in Thai noun phrases. Syntax $17(4), 299-342$.

Kandybowicz, Jason. 2006. Comp-trace effects explained away. In Donald

Baumer, David Montero \& Michael Scanlon (eds.), Proceedings of the 25th West Coast Conference on Formal Linguistics (WCCFL), 220-228. Somerville, MA: Cascadilla Press.

Karimi, Yadgar. 2007. Kurdish ezafe construction: implications for DP structure. Lingua 117(12), 2159-77.

Kayne, Richard S. 1975. French syntax: the transformational cycle. Cambridge, MA: MIT Press. 
Kayne, Richard S. 2010. Antisymmetry and the lexicon. In Richard S. Kayne (ed.), Comparisons and contrasts, 165-189. Oxford: Oxford University Press.

Koopman, Hilda. 1984. The syntax of verbs. Dordrecht: Foris.

Koster, Jan. 1978. Locality principles in syntax. Dordrecht: Foris.

LaCharité, Darlene \& Jean Wellington. 1999. Passive in Jamaican Creole. Journal of Pidgin and Creole Languages 14(2), 259-283.

Landau, Idan. 2000. Elements of control: structure and meaning in infinitival constructions. Studies in Natural Language and Linguistic Theory. Dordrecht, Boston: Kluwer Academic Publishers.

Landau, Idan. 2004. The scale of finiteness and the calculus of control. Natural Language and Linguistic Theory 22(4), 811-877.

Landau, Idan 2006. Severing the Distribution of Pro from Case. Syntax 9(2), 15370.

Landau, Idan. 2008. Two routes of control: evidence from case transmission in Russian. Natural Language and Linguistic Theory 26, 877-924.

Landau, Idan. 2014. A two-tiered theory of Control. Cambridge, MA: MIT Press. Larson, Richard K. \& Hiroko Yamakido. 2008. Ezafe and the deep position of nominal modifiers. In Louise McNally \& Chris Kennedy (eds.), Adjectives and adverbs: syntax, semantics, and discourse, 43-70. Oxford: Oxford University Press.

Legate, Julie-Anne. 2008. Morphological case and abstract Case. Linguistic Inquiry 39, 55-101.

Legate, Julie-Anne. 2012. Types of Ergativity. Lingua 122(3), 181-191.

Legate, Julie-Anne. 2014. Voice and v. Lessons from Achenese. Cambride, MA: MIT Press.

Li, Yen-hui Audrey. 1985. Abstract case in Mandarin Chinese. Los Angeles, CA.: University of Southern California dissertation.

Li, Yen-hui Audrey. 1990. Order and constituency in Mandarin Chinese. Dordrecht: Kluwer Academic Publishing.

Li, Yen-Hui Audrey. 2005. Ellipsis and missing objects. Yuyan Kexue [Linguistic Sciences] 4.3-19.

Li, Yen-Hui Audrey. 2007. Theories of empty categories and Chinese null elements. Yuyan Kexue [Linguistic Sciences] 6, 37-47.

Li, Yen-hui Audrey. 2008. Case, 20 Years Later. In Marjorie K.M. Chan \& Hana Kang (eds.), Proceedings of the 20th North American Conference on Chinese Linguistics (NACCL-20), 41-68. Columbus, Ohio: The Ohio State University.

Lin, Jonah T. H. 2011. Finiteness of clauses and raising of arguments in Mandarin Chinese. Syntax 14(1), 48-73.

Lin, Jo-wang. 2010. A Tenseless Analysis of Mandarin Chinese Revisited: A Response to Sybesma 2007. Linguistic Inquiry 41(2), 305-329.

Madugu, Isaac S. George. 1976. Yoruba adjectives have merged with verbs: or are they just emerging? Journal of West African Languages 11(1-2), 1-18.

Maling, Joan. 1984. Non-clause bound reflexives in Modern Icelandic. Linguistics and Philosophy 7, 211-41.

Marantz, Alec. 1991. Case and Licensing. In Germán F. Westphal, Benjamin Ao \& He-Rahk Chae (eds.), Proceedings of the 8th Eastern States Conference on Linguistics (ECOL), 234-253.

Markman, Vita. 2009. On the parametric variation of case and agreement. Natural Language \& Linguistic Theory 27, 379-426. 
Martin, Roger A. 1996. A Minimalist theory of PRO and Control. Storrs, CT: UConn dissertation.

McFadden, Thomas. 2004. The position of morphological case in the derivation: A study on the syntax-morphology interface. Philadelphia, PA: UPenn dissertation.

Miyagawa, Shigeru. 2010. Why Agree? Why Move: unifying agreement-based and discourse configurational languages. Cambridge, MA.: MIT Press.

Morimoto, Yukiko. 2006. Agreement properties and word order in comparative Bantu. ZAS Papers in Linguistics 43, 161-88.

Morimoto, Yukiko. 2000. Discourse-configurationality in Bantu morphosyntax. Stanford, CA.: Stanford University dissertation.

Morimoto, Yukiko. 2006. Agreement properties and word order in comparative Bantu. ZAS Papers in Linguistics 43, 161-188.

Müller, Gereon, and Daniela Thomas. 2015. Three-way systems do not exist. Handout of talk at the meeting of the SLE, Leiden.

Nikolaeva, Irina \& Andrew Spencer. 2012. Possession and modification - a perspective from Canonical Typology. In Dunstan Brown, Marina Chumakina \& Grev Corbett (eds.), Canonical morphology and syntax, 207-38. Oxford: Oxford University Press.

Nikolaeva, Irina (ed.) 2007. Finiteness. Oxford: Oxford University Press.

Ogunbowale, P. R. The essentials of the Yoruba language. London: University of Lodon Press Ltd.

Pan, Victor, and Paul, Waltraud. 2014. Finiteness in Mandarin Chinese and the basic syntax of kěnéng. Ms., Paris.

Paul, Waltraud. 2002. Sentence-internal topics in Mandarin Chinese: The case of object preposing. Language and Linguistics 3, 695-714.

Pesetsky, David. 2014. Russian case morphology and the syntactic categories. Cambridge, MA: MIT Press.

Pesetsky, David \& Esther Torrego. 2001. T-to-C movement: Causes and consequences. In Michael Kenstowicz (ed.), Ken Hale: A life in language, 355426. Cambridge, MA: MIT Press.

Pesetsky, David \& Esther Torrego. 2004. Tense, Case, and the nature of syntactic categories. In Jacqueline Guéron \& Jacqueline Lecarme (eds.), The Syntax of Time, 495-538. Cambridge, MA: MIT Press.

Plann, Susan. 1986. On Case-Marking Clauses in Spanish: Evidence against the Case Resistance Principle. Linguistic Inquiry 17, 336-345.

Preminger, Omer. 2014. Agreement and its failures. Cambridge, MA: MIT Press.

Philip, Joy N. 2012. Subordinating and coordinating linkers. London, UK: UCL dissertation.

Philip, Joy N. 2013. (Dis)harmony, the Head-Proximate Filter, and linkers. Journal of Linguistics 49, 165-213.

Pollard, Carl \& Ivan Sag (1992). Anaphors in English and the Scope of Binding Theory. Linguistic Inquiry 23, 261-303.

Postal, Paul. 1971. Crossover Phenomena. New York: Holt, Rinehart and Winston.

Potsdam, Eric \& Jeffrey T. Runner. 2001. Richard returns: Copy Raising and its implications. In Mary Andronis, Christopher Ball, Heidi Elston \& Sylvain Neuvel (eds.), Proceedings of the 37th Chicago Linguistics Society (CLS), 45368. Chicago: Chicago Linguistic Society.

Prasithrathsint, Amara. 2000. Adjectives as verbs in Thai. Linguistic Typology 4, 
251-271.

Progovac, Ljiliana. 1993. Non-augmented NPs in Kinande as Negative Polarity Items. In Sam Mchombo (ed.), Theoretical aspects of Bantu grammar, 257270. Stanford, CA: CSLI Publications.

Pulleybank, Douglas. 1986. Clitics in Yoruba. In Hagit Borer (ed.), Syntax and Semantics 9: the Syntax of Pronominal Clitics, 43-64. New York: Academic Press.

Quicoli, A. Carlos. 1996. Inflection and parametric variation: Portuguese vs. Spanish. In Robert Freidin (ed.), Current Issues in comparative grammar, 4680. Dordrecht: Kluwer.

Raposo, Eduardo. 1987. Case theory and Infl-to-Comp: The inflected infinitive in European Portuguese. Linguistic Inquiry 18(1), 85-109.

Reinhart, Tanya and Eric Reuland. 1993. Reflexivity. Linguistic Inquiry 24, 657 720.

Reuland, Eric and Dagmar Schadler. 2011. Approaching body part reflexives. Technical report for The Afranaph Development Workshop.

Rizzi, Luigi. 1982. Issues in Italian syntax. Dordrecht: Foris.

Rizzi, Luigi. 1990. On the anaphor-agreement effect. Rivista di Linguistica 2, 27 42.

Rizzi, Luigi. 1997. The Fine Structure of the Left Periphery. In Liliane Haegeman (ed.), Elements of grammar, 281-337. Dordrecht: Kluwer.

Rizzi, Luigi. 2015. Cartography, Criteria, and Labeling. In Ur Shlonsky (ed.), Beyond the Functional Sequence, 314-338. New York: Oxford University Press.

Roberts, Ian. 2010. Agreement and head movement: Clitics, incorporation, and defective goals. Cambridge, MA: MIT Press.

Rowlands, Evan Celyn. 1969. Teach yourself Yoruba. London: English Universities Press.

Sabel, Joachim, and Jochen Zeller. 2006. WH question formation in Nguni. In by John Mugane, John P. Hutchison \& Dee A. Worman (eds.), Selected Proceedings of the 35th Annual Conference on African Linguistics, 271-283. Somerville, MA: Cascadilla Proceedings Project.

Saito, Mamoru. 2007 Notes on East Asian argument ellipsis. Language Research 43, 203-227.

Samiian, Vida. 1994. The ezafe construction: Some implications for the theory of X-Bar syntax. In Meshi Marashi (ed.), Persian Studies in North America, 17-41. Bethesda, MD: Iranbooks.

Schladt, Mathias. 2000. The typology and grammaticalization of reflexives. In Zygmunt Frajzyngier \& Traci Curl (eds.), Reflexives: Forms and Functions, 103-124. Amsterdam: John Benjamins.

Sheehan, Michelle. 2011. A note on Case-assignment to CP. Snippets 24, 18-19.

Sheehan, Michelle. 2014. Portuguese, Russian and the theory of Control. In HsinLun Huang, Ethan Poole \& Amanda Rysling (eds.), Proceedings of the 43rd Annual Meeting of the North East Linguistic Society (NELS), 115-26. Amherst, MA: GLSA.

Sheehan, Michelle. 2015a. Control of inflected infinitives in European Portuguese. To appear in Anabela. Gonçalves \& Ana-Lúcia Santos (eds.), Complement clauses in Portuguese: syntax and acquisition. Amsterdam: John Benjamins. 
Sheehan, Michelle. 2015b. Parameterising ergativity: an inherent case approach. To appear in Jessica Coon, Diane. Massam \& Lisa Travis (eds.), The Oxford Handbook of Ergativity. Oxford: Oxford University Press.

Sheehan, Michelle. 2016. On the difference between exhaustive and partial control. To appear in F. Cognola \& J. Casalicchio (eds.), Understanding Null Subjects: a Synchronic and Diachronic Perspective. OUP.

Sheehan, Michelle \& Jenneke van der Wal. 2016. Do we need abstract Case? In Kim, Kyeong-min et al. (eds), Proceedings of the 33rd West Coast Conference on Formal Linguistics, 351-360. Somerville, MA: Cascadilla Proceedings Project.

Sigurðsson, Halldór. 1991. Icelandic case-marked PRO and the licensing of lexical arguments. Natural Language and Linguistic Theory 9, 327-363.

Sigurðsson, Halldór. 2008. The case of PRO. Natural Language \& Linguistic Theory 26, 403-450.

Sigurðsson, Halldór. 2012. Minimalist C/case. Linguistic Inquiry 43, 191-227.

Sitaridou, Ioanna. 2006. The (dis)association of tense, phi-features EPP and nominative case: Case studies from Romance and Greek. In João Costa \& Maria Cristina Figeiredo Silva (eds.), Studies on agreement, 243-260. Amsterdam: John Benjamins.

Stowell, Timothy. 1981. Origins of phrase structure. Cambridge, MA: MIT dissertation.

Sudmuk, Cholthicha. 2003. The thuuk construction in Thai. In Miriam Butt \& Tracy Holloway King (eds), Proceedings of the LFG03 conference, 402-431.

Sundaresan, Sandhya \& Thomas McFadden. 2009. Subject distribution in Tamil and other languages: Selection vs. Case. Journal of South Asian Languages 2(1). 5-34.

Sundaresan, Sandhya. 2014. Making sense of silence: Finiteness and the (OC) PRO vs. pro distinction. Natural Language \& Linguistic Theory 32. 59-85.

Sundaresan, Sandhya. 2015. Anaphora vs. agreement: introducing a new kind of Anaphor Agreement Effect. Manuscript available at lingbuzz/002167.

Szabolcsi, Anne. 2009. Overt nominative subjects in infinitival complements cross-linguistically: Data, diagnostics, and preliminary analyses. New York University Working Papers in Linguistics 2, 1-55.

Tada, Hiroaki. 1993. A/A-Bar Partition in Derivation. PhD Dissertation, MIT

Tang, Chih-Chen Jane.1990. Chinese phrase structure and the extended X-Theory. Ithaca, NY: Cornell University dissertation.

Tang, Ting.-Chi. 2000. Finite and nonfinite clauses in Chinese. Language and Linguistics 1, 191-214.

Thráinsson, Höskuldur. 1979. On complementation in Icelandic. New York: Garland.

Travis, Lisa. 1984. Parameters and effects of word order variation. Cambridge, MA: MIT dissertation.

Tsai, W.-T. Dylan. 1995. Visibility, complement selection and the case requirement of CP. Journal of East Asian Linguistics 4, 281-312.

Tucker, Matthew A. 2012. Even more on the Anaphor Agreement Effect: when binding does not agree. Under review.

Van Urk, Coppe. 2010. On obligatory control: A movement and PRO approach. Unpublished manuscript, MIT, Cambridge, MA. 
Van de Velde, Mark L. O. 2013. The Bantu connective construction. In Anne Carlier \& Jean-Christophe Verstraete (eds.), The Genitive, 217-252. Amsterdam: John Benjamins.

Van der Wal, Jenneke. 2009. Word order and information structure in MakhuwaEnahara. Utrecht: LOT.

Van der Wal, Jenneke. 2010. Makhuwa non-subject relatives as participial modifiers. Journal of African Languages and Linguistics 31(2), 205-231.

Van der Wal, Jenneke. 2015a. Evidence for abstract Case in Bantu. Lingua 165, 109-132.

Van der Wal, Jenneke. 2015b. Bantu object clitics as defective goals. Revue Roumaine de Linguistique LX (2-3), 277-296.

Van der Wal, Jenneke. 2015c. Bantu Syntax. Oxford Handbooks Online.

Varlokosta, Spyridoula. 1994. Issues on Modern Greek sentential complementation. University of Maryland dissertation.

Veenstra, Tonjes. 1990. Serial verb constructions in Jamaican Creole and grammatical theory. MA thesis, University of Amsterdam.

Vergnaud, Jean-Roger. 1977/2008. Letter to Noam Chomsky and Howard Lasnik on "Filters and control". In Robert Freidin, Carlos P. Otero \& Maria Luisa Zubizarreta (eds.), Foundational issues in linguistic theory: Essays in honor of Jean-Roger Vergnaud, 3-15. Cambridge, MA: MIT Press.

Winford, Donald. 1993. Predication in Carribean English Creoles. Amsterdam: John Benjamins.

Woolford, Ellen. 1999. More on the anaphor agreement effect. Linguistic Inquiry $30(2), 257-287$.

Yoneda, Nobuko. 2011. Word order in Matengo (N13): Topicality and informational roles. Lingua 121(5), 754-771.

Zaenen, Annie, Joan Maling, and Höskuldur Thráinsson. 1985. Case and Grammatical Functions: The Icelandic Passive. Natural Language \& Linguistic Theory 3, 441-83.

Zerbian, Sabine. 2006. Expression of information structure in Northern Sotho. Berlin: Humboldt University dissertation.

Zerbian, Sabine. 2007. The subject/object asymmetry in Northern Sotho. In Kerstin Schwabe \& Susanne Winkler. On information structure, meaning and form: generalizations across languages, 323-364. Amsterdam: John Benjamins. 